\title{
Long-term changes in the acid and salt concentrations of the Greenland Ice Core Project ice core from electrical stratigraphy
}

\author{
Eric W. Wolff, ${ }^{1}$ John C. Moore, ${ }^{2}$ Henrik B. Clausen, ${ }^{3}$ Claus U. Hammer, ${ }^{3}$ \\ Josef Kipfstuhl, ${ }^{4}$ and Katrin Fuhrer ${ }^{5}$
}

\begin{abstract}
Continuous electrical records covering a climatic cycle are presented for the Greenland Ice Core Project deep ice core from Greenland. Electrical conductivity measurement (ECM) measures the acid content of the ice, and the dielectric profile (DEP) responds to acid, ammonium, and chloride. All features seen can be explained by chemical changes in the ice, and there is no evidence so far for any major change in electrical response with depth or age of the ice. Both records are dominated by the acidity of the ice which varies strongly from acidic in warm periods to alkaline in cold periods, controlled by neutralization by alkaline dust (calcareous and other mineral dust). When $\mathrm{Ca}$ is low, the acidity (mainly nitric acid) has a fairly constant background level throughout the cycle, with slightly lower values in ice believed to be from the last interglacial. Ca has to rise only slightly to neutralize the available acidity, so that acidity is a highly nonlinear reflection of climate changes. If neutralization occurred in the aerosol (rather than in the ice), then the number of cloud condensation nuclei over parts of the northern hemisphere could have been reduced, leading to reduced cloud albedo. This nonlinear feedback may have some importance for modeling of climate change. When both acid and ammonium levels are low, the DEP signal can be used to give a rapid indication of chloride trends.
\end{abstract}

\section{Introduction}

The 3028-m-deep ice core obtained by the Greenland Ice Core Project (GRIP) from Summit, central Greenland, has provided a detailed record of past climate [Johnsen et al., 1992a; Dansgaard et al., 1993; GRIP Project Members, 1993]. The record has been compared with that obtained at a nearby site by the Greenland Ice Sheet Project (GISP2) team [Grootes et al., 1993; Taylor et al., 1993a]. The excellent agreement in the top $2700 \mathrm{~m}$ (approximately $90 \mathrm{kyr}$ ) means that the record in this section (covering the Holocene and most of the last glacial, including many rapid climate changes (Dansgaard-Oeschger events)) can be considered firmly established [GRIP Project Members, 1993].

The basic climate signal is deduced from measurements of oxygen and deuterium isotopes in the ice. However, a huge range of other physical properties and chemical concentrations have been measured on the core, and these make other paleoenvironmental parameters accessible. For example, the methane record [Chappellaz et al., 1993] shows how one of the climate forcing factors varied almost synchronously with the temperature signal, while chemical data from both the GRIP

\footnotetext{
${ }^{1}$ British Antarctic Survey, Natural Environment Research Council, Cambridge, England.

${ }^{2}$ Arctic Centre, University of Lapland, Rovaniemi, Finland.

${ }^{3}$ Department of Geophysics, Niels Bohr Institute, University of Copenhagen, Copenhagen, Denmark.

${ }^{4}$ Alfred Wegener Institute, Bremerhaven, Germany.

${ }^{5}$ Physikalisches Institut, University of Bern, Bern, Switzerland.

Copyright 1995 by the American Geophysical Union.

Paper Number 95JD01174.

0148-0227/95/95JD-01174\$05.00
}

[Fuhrer et al., 1993] and GISP2 core [Mayewski et al., 1993] give clues as to how atmospheric circulation varied as climate changed.

Parameters that can be measured continuously and at high resolution are especially valuable [Hammer, 1989]. Continuous flow methods were used to measure a number of chemical species in this way [e.g. Fuhrer et al. 1993]. Electrical methods are particularly rapid and simple to make in the field, and the data can be used to deduce important chemical concentrations in the ice.

Various electrical measurements were made on the GRIP core. The electrical conductivity measurement (ECM) method is a well-established method [Hammer, 1980], operating effectively at DC, that has been used on previous deep cores [Hammer et $a l ., 1985]$. It responds essentially only to the acidity of the ice, even in the presence of large excesses of neutral salt [Moore et al., 1992b]. In Greenland, the major part of the background acidity is nitric acid, while most of the large volcanic acid spikes are mainly sulphuric acid. ECM was also measured on the GISP2 core [Taylor et al., 1993b], and the ECM records from both GRIP and GISP2 have been presented at very low resolution in a paper that was concerned with comparing the stratigraphy of the two cores [Taylor et al., 1993a]. The dielectric profiling (DEP) method [Moore and Paren, 1987] makes measurements at $\mathrm{AC}$ frequencies, and responds to acid and neutral salt concentrations [Moore et al., 1989, 1992a, b] and also to ammonium concentrations in the ice [Moore et al., 1994]. Until now, DEP had been used only on shallow cores, and in Greenland it was available only at GRIP. A third electrical method, developed by scientists from the Alfred Wegener Institute, and based on a two-point electrical system, was also used on the GRIP core. This method makes measurements at a number of frequencies, but the data are not yet processed to their final state and will be presented separately. 
In the field, the electrical methods were invaluable for pinpointing interesting sections of the core requiring more detailed subsampling for other analyses. In addition, the electrical methods are the only ones used to obtain information about the background acidity of the atmosphere, and by using the two methods together other chemical information can be obtained. The resolution of the records means that they can assist with annual layer counting, used to date the core. In this paper we present the continuous ECM and DEP records from the GRIP core. We look at the data on various levels of detail and interpret them in terms of changes in the background chemistry of the atmosphere. The relationship, seen in the entire data set, between changes in climate and changes in the chemistry identified from the electrical records, will be discussed.

\section{Methods and Analysis}

Generally, cores (each up to $2.5 \mathrm{~m}$ long) were measured by both ECM and DEP in a science trench a few meters below the snow surface a few days after drilling. However, the ice from 932 to $1300 \mathrm{~m}$, and from 702 to $770 \mathrm{~m}$, was measured a year after drilling. Cores were measured in each of 3 years: from approximately $138 \mathrm{~m}$ to $702 \mathrm{~m}$ in 1990 , from $702 \mathrm{~m}$ to $932 \mathrm{~m}$ and $1300 \mathrm{~m}$ to $2300 \mathrm{~m}$ in 1991, the remaining sections in 1992 . The top $137 \mathrm{~m}$ of core, drilled in 1989, was not analyzed for DEP.

\subsection{ECM}

In the ECM method, the cores were placed in a cradle, and a microtome knife was used to prepare a fresh, flat surface along the length of the core. A pair of brass electrodes (approximately $1.5 \mathrm{~mm}^{2}$ in area and about $1 \mathrm{~cm}$ apart) was run along the ice surface at a speed of order $25 \mathrm{~cm} \mathrm{~s}^{-1}$, while a high voltage (1250 V) was applied across the electrodes. The current (microamperes) flowing between the electrodes was recorded both as chart recorder output and in digital form at a rate generally $=1 / \mathrm{mm}$. The electrodes were held against the ice, and moved, manually, to secure sufficient pressure and contact on the ice surface, irrespective of the physical state of the ice (e.g. broken ice cores). However, the electrodes were operated only by a small number of experienced personnel to avoid erroneous operation of the electrodes. Measured currents were corrected from the ice core temperature (in the range $-25^{\circ} \mathrm{C}$ to $-12^{\circ} \mathrm{C}$ ) to $14^{\circ} \mathrm{C}$, using an activation energy of $0.23 \mathrm{eV}\left(22 \mathrm{~kJ} \mathrm{~mol}^{-1}\right)$ [Hammer, 1983]. It takes $\approx 10 \mathrm{~s}$ to run a core, with a total procedural time of about $15 \mathrm{~min}$. The calibration from current to acidity used for other records [Hammer, 1980] seems not to be appropriate for central Greenland ice cores drilled and measured in recent years [Moore et al., 1994; Clausen et al., 1995]. Because there is quite a lot of scatter, calibration on the ECM signal has been performed, and we have adopted [Moore et al., 1994]:

$$
\left[\mathrm{H}^{+}\right]=0.03 I^{2}
$$

where $\left[\mathrm{H}^{+}\right]$is the acid concentration in micromolar (micromoles per liter) and $I$ is current in microamperes (see also discussion in Clausen et al. [1995]). Other species (ammonia, sea salt, etc.) give no increase in ECM signal [Moore et al., 1992b, 1994], so that it is acceptable to quote ECM as an acid concentration, rather than as an arbitrary current which would vary between ECM systems. However, it is unclear what the true meaning of this acidity is for the residual signal seen in alkaline ice (see later). The ECM $\mathrm{H}^{+}$values are often stored as $1-\mathrm{cm}$ averages for comparison with other data sets.

\subsection{DEP}

DEP measurements were made with two different instruments. The main set of measurements, comprising the bulk of data reported here, were made with the "main" DEP system, which works on a similar principle to that described before [Moore and Paren, 1987; Moore et al., 1992b]. DEP is an AC technique, requiring no special ice surface preparation, and not requiring physical contact between the electrodes and the ice. The whole core was placed onto a lower curved continuous aluminium electrode. A set of curved segmented aluminium electrodes, each $2 \mathrm{~cm}$ across, was closed over the core. Using an applied voltage of $1 \mathrm{~V}$, the dielectric response of each 2-cm section was determined using a computer-controlled bridge sweeping the AFLF frequency range. The electrodes were all coated with a nonconducting film, so there was no direct contact with the ice. For each 2-cm section, one top electrode was "active," while the remainder acted as guard electrodes. The computer made each segment active in turn, so that a profile of dielectric properties along the core was obtained. As set up for the GRIP core, with $2-\mathrm{cm}$ resolution, and using 20 frequencies between $120 \mathrm{~Hz}$ and $300 \mathrm{kHz}$, it took about $20 \mathrm{~min}$ to analyze a $2-\mathrm{m}$ core length. Note that there is a considerable increase in resolution and speed compared to systems reported previously.

Raw DEP data consist of conductance and capacitance measurements at a range of frequencies that span the main dielectric dispersion of ice [Hobbs, 1974]. From a range of properties that can be derived, $\sigma_{\infty}$, the high-frequency limit of the conductivity, has proved to be the most useful and is reported throughout this paper. Measurements were made at trench temperatures between $-25^{\circ}$ and $-10^{\circ} \mathrm{C}$. They have been normalized to $-15^{\circ} \mathrm{C}$, using an activation energy of $0.5 \mathrm{eV}(48 \mathrm{~kJ}$ $\mathrm{mol}^{-1}$ ) to correct the background part of the conductivity due to pure ice, and $0.22 \mathrm{eV}$ (average for salt and acid from previous studies) to correct everything above this background level [Moore et al., 1992b, 1994]. As noted elsewhere, there were some difficulties in making this correction, because at some depths (mainly for the core measured in 1991) the temperature of the ice was still equilibrating when our measurements were made, so that the ice temperature is poorly known.

One further correction has been made to some of the data. There appears to be some dependence of $\sigma_{\infty}$ on the electrode position (i.e., which of the 120 top electrodes was used). This is not seen clearly in the more variable (and less well temperature-corrected) data from earlier years, but can be seen in less variable sections of the 1992 data, where it imposes an uncertainty of order $1 \mu \mathrm{S} \mathrm{m} \mathrm{m}^{-1}$ on individual values; because values near the ends of the electrode sets are slightly higher than

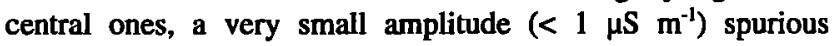
cyclicity (period approximately $2.4 \mathrm{~m}$ ) is also seen. Analysis of the data from $2479-2532 \mathrm{~m}$ (confirmed on another section around $2900 \mathrm{~m}$ ) has enabled a correction to be made to the data from $2300 \mathrm{~m}$ down. This has no noticeable effect on presentations of the data at low resolution but does reduce the noise and remove the cyclicity, making detailed small features easier to see in some of the figures. No correction was made to data above $2300 \mathrm{~m}$, as we cannot be certain that the same correction would apply; an uncertainty of order $1 \mu \mathrm{S} \mathrm{m} \mathrm{m}^{-1}$ therefore has to be accepted from this cause in the shallower data. 
The temperature-corrected $\sigma_{\infty}$ values depend on acidity, on some component (probably chloride) of sea salt, and on ammonium concentrations [Moore et al., 1994]. It seems as if all the peaks seen in the profile can be explained by these three components, although this paper will examine again what is happening in the highly alkaline, chemical-laden glacial sections of the ice. The calibration of the DEP against chemistry will be discussed below.

Further measurements were made with a second instrument, a high-resolution DEP (HRDEP), described by Moore [1993]. In this system, a 55-cm length of core with one flat face was again rested in a curved aluminium bottom electrode. The top electrode consisted of a narrow $(1-3 \mathrm{~mm})$ flat electrode (with guards on either side) mounted on a polymethylmethacrylate block. This was run along the ice surface at $1 \mathrm{~cm} \mathrm{~s}^{-1}$, and capacitance and conductance were measured at just one frequency, $50 \mathrm{kHz}$. This method is not quantitative but gives a qualitative estimate of changes in $\sigma_{\infty}$ along the core at a resolution of about $2 \mathrm{~mm}$. HRDEP was used on about one core section in every 20 that was measured in 1991, and on most of the core measured in 1992. A few of the data are reported here for high-resolution comparison with ECM data.

\subsection{DEP calibration}

The DEP $\sigma_{\infty}$ is expected to be caused by four chemical components, and we expect these to be operating in parallel, and therefore to be additive, so that we can treat them separately:

1. Pure ice single crystals at $-15^{\circ} \mathrm{C}$ have a conductivity of 9 $\mu \mathrm{S} \mathrm{m}^{-1}$ [Camplin et al., 1978], and this should be present throughout the core.

2. The response to acid $\left(\mathrm{H}^{+}\right)$has been shown to be linear [Moore et al., 1989, 1994]. The coefficient relating $\sigma_{\infty}$ to $\left[\mathrm{H}^{+}\right]$ seems to be reasonably constant with depth [Moore et al., 1994]. A fuller analysis, comparing the 2-cm DEP data with 2-cm averaged $\mathrm{ECM}$ data $\left(\mathrm{H}^{+}>0.3 \mu M\right.$ only) for every 20 -m section of the core has confirmed this, and we estimate the coefficient to be approximately $4 \pm 1 \mathrm{~S} \mathrm{~m}^{-1} M^{-1}$ at $-15^{\circ} \mathrm{C}$. Errors in this calculation arise partly from uncertainty in the ECM calibration [Clausen et al., 1995], and partly from the difficulties we had with the DEP temperature correction in some parts of the core.

3. Ammonium salts have no direct effect on the ECM signal but add to the signal in DEP. The coefficient relating $\sigma_{\infty}$ to $\left[\mathrm{NH}_{4}{ }^{+}\right]$has been estimated at $1.0 \pm 0.2 \mathrm{~S} \mathrm{~m}^{-1} M^{-1}$ at $-15^{\circ} \mathrm{C}$ [Moore et al., 1994].

4. Sea salt also affects only the DEP response [Moore et al., 1992a]. In the GRIP core, sea salt is high only in the alkaline, dusty, ice age parts of the core, where many chemical species vary in phase. The coefficient relating $\sigma_{\infty}$ to $\left[\mathrm{Cl}^{-}\right]$at $-15^{\circ} \mathrm{C}$ is $0.55 \mathrm{~S} \mathrm{~m}^{-1} \mathrm{M}^{-1}$ [Moore et al., 1992a].

Overall, therefore the DEP $\sigma_{\infty}$ signal at $-15^{\circ} \mathrm{C}$ should be quite well described as

$$
\sigma_{\infty}=9+4\left[\mathrm{H}^{+}\right]+1\left[\mathrm{NH}_{4}^{+}\right]+0.55\left[\mathrm{Cl}^{-}\right]
$$

where $\sigma_{\infty}$ is in microsiemens per meter and chemical concentrations are in micromolar. One use we might make of this equation is to use the ECM data to remove the acid part of the $\sigma_{\infty}$ and then investigate the chemical signal in what remains. The uncertainty in the calibration is such that, in acidic ice, it is hard to see any but the largest changes in other chemistry. However, in alkali ice, the correction will be quite small, and the DEP signal due to sea salt and ammonium should be clear.

\section{Continuous Electrical Records}

\subsection{Nature of the data}

Both the ECM and DEP electrical records consist of a varying background, on which are superimposed a number of very large peaks, lasting just 1-3 years, due to the input of acid from volcanic eruptions. In this paper we are interested in the background chemistry of the ice, and the detailed volcanic eruption record will be described separately (the record of the top $300 \mathrm{~m}$ is given by Clausen et al. [1995]). The electrical signals over two typical volcanic peaks are shown in Figure 1 . Over such peaks, the two methods are measuring essentially the same thing. For all subsequent discussions in this paper, we have removed the large volcanic peaks. This was done by identifying all data points $(2 \mathrm{~cm}$ resolution) where the ECM value was $\geq 4$ $\mu M$. For all these points, both the ECM and DEP values were replaced by the mean of five nonvolcanic data values on the flanks of the peak. In total, $19.14 \mathrm{~m}$ of core out of $2900 \mathrm{~m}(957$ data points in approximately 297 separate peaks) were replaced by this filter. The deepest replacement was made at $2460 \mathrm{~m}$ depth (approximately $55 \mathrm{kyr}$ ).

For most of this paper, where the long-term record is discussed, data averaged over $55 \mathrm{~cm}$ blocks are presented (Figures 2 and 3). The DEP data are shown on linear scales. The ECM data are shown on either linear or logarithmic scales, depending on the context. The entire records are shown in
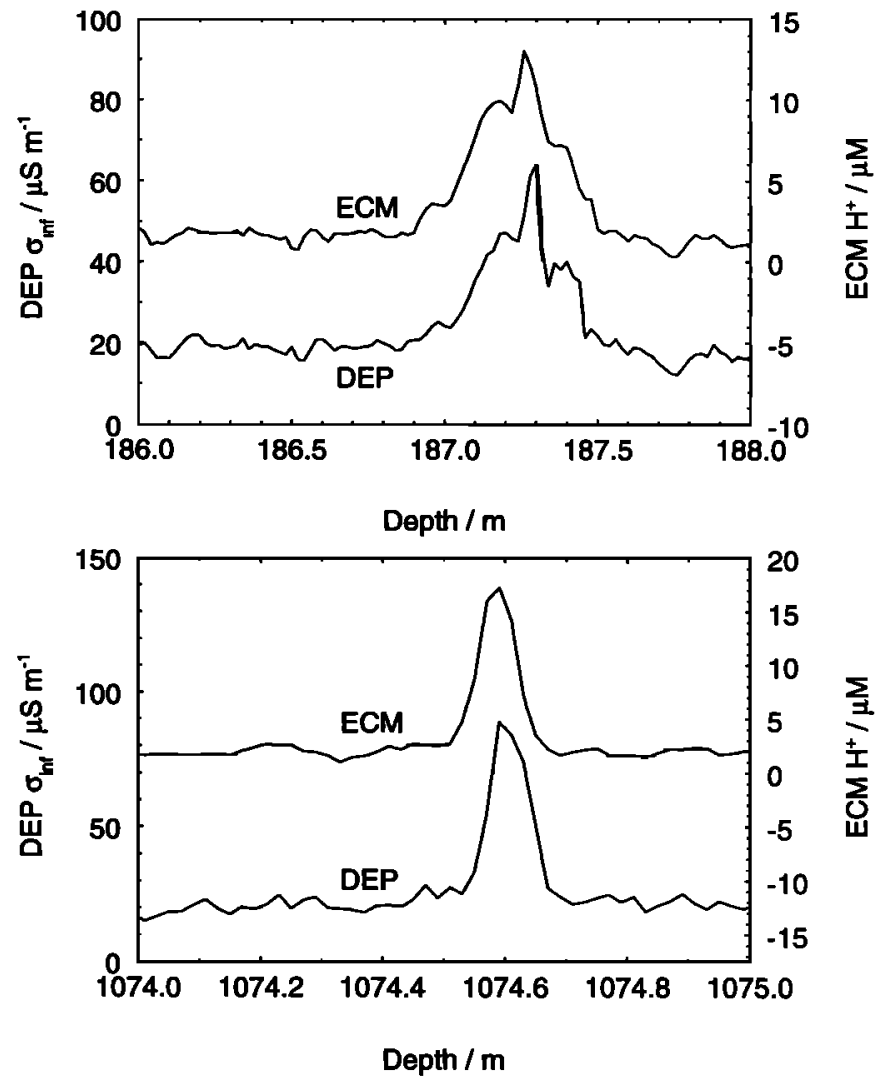

Figure 1. The electrical signals across two typical medium-large volcanic events. The dielectric profiling (DEP) signal is at $2-\mathrm{cm}$ resolution; the electrical conductivity measurement (ECM) signal has been averaged to $2-\mathrm{cm}$ sections. (a) Volcano identified as 1259 A.D. [Clausen et al., 1995]; (b) at $1074.6 \mathrm{~m}$, approximately 6000 years B.P. 


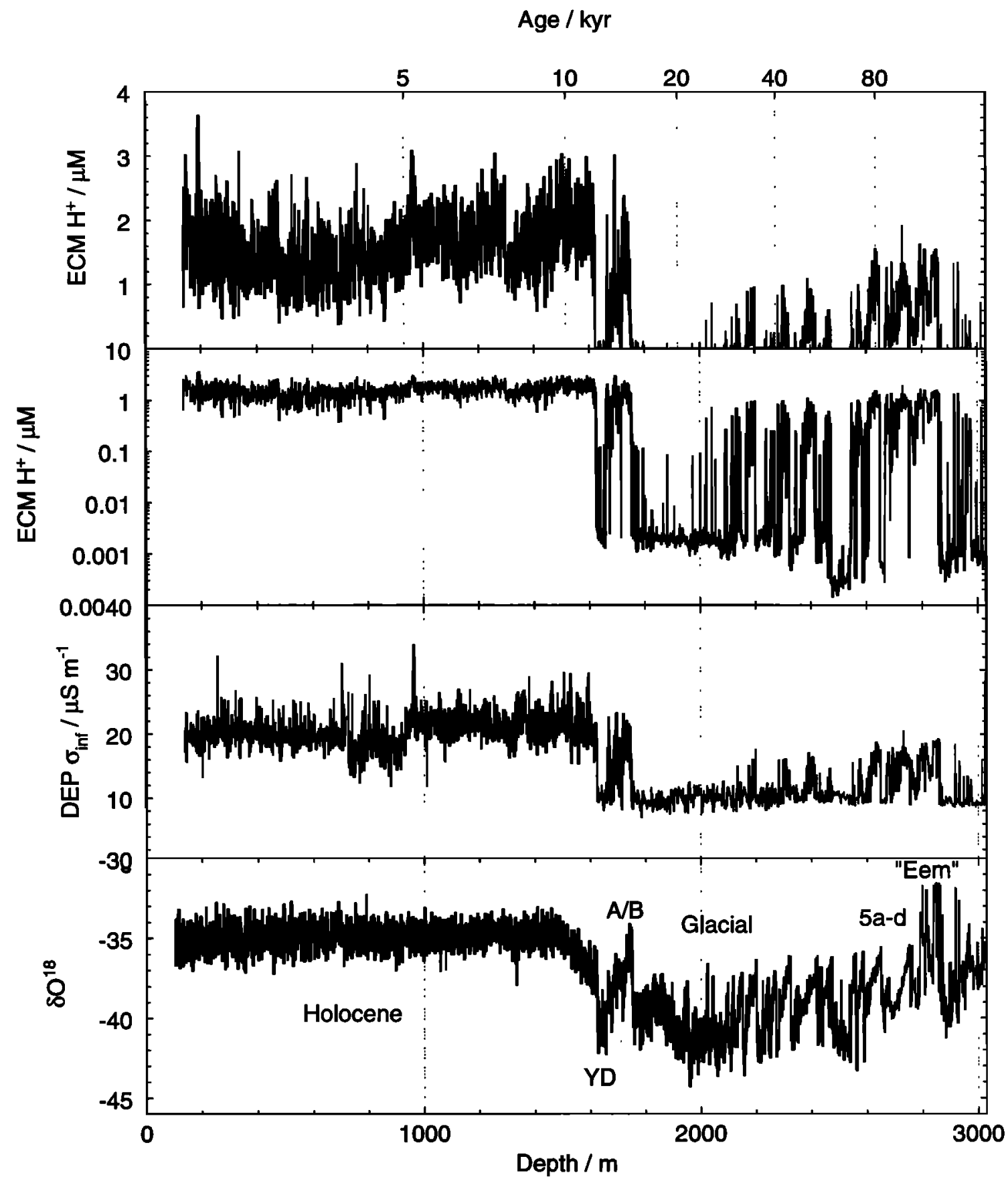

Figure 2. The electrical records (in 55-cm averages) for the entire GRIP ice core, along with the oxygen isotope record [Dansgaard et al., 1993]. The electrical conductivity measurement (ECM) signal (converted to $\mathrm{H}^{+}$as described in the text) is given on both linear and logarithmic scales. Note that the records are depth, not time averaged, so that the data near the surface integrate far shorter periods than those at depth, and appear noisier for this reason. DEP, dielectric profile; A/B, Allerod/Bolling period; YD, Younger Dryas period; Eem, Eemian period.

Figures 2 and 3, along with the oxygen isotope record [Dansgaard et al., 1993], which is generally considered to be a proxy for atmospheric temperature. Note that the data are presented here as depth averages, not time averages, so that the data nearer the surface (averaging of order 2 years each) are naturally noisier than those deep in the core, where long time periods (centuries) are integrated in each average. Some general features stand out from the entire profile. First, the two electrical records show very similar features on the broad scale. In detail, there are some important differences, which will be discussed later. Second, across the entire data set, there is a close correlation between gross changes in the oxygen isotope ratio and the electrical signals. In isotopically warm periods, the electrical signals are generally high (ECM H $\mathrm{H}^{+} 0.5-2 \mu M, \sigma_{\infty} 15-25 \mu \mathrm{S} \mathrm{m}^{-1}$ ); in isotopically cold periods, the electrical signals are low (ECM $\left.\mathrm{H}^{+}<0.1 \mu M, \sigma_{\infty} 9-12 \mu \mathrm{S} \mathrm{m}^{-1}\right)$. There are very few points that are intermediate between these two states. This reflects the general rule that in warmer periods, the ice is acidic, while in colder 


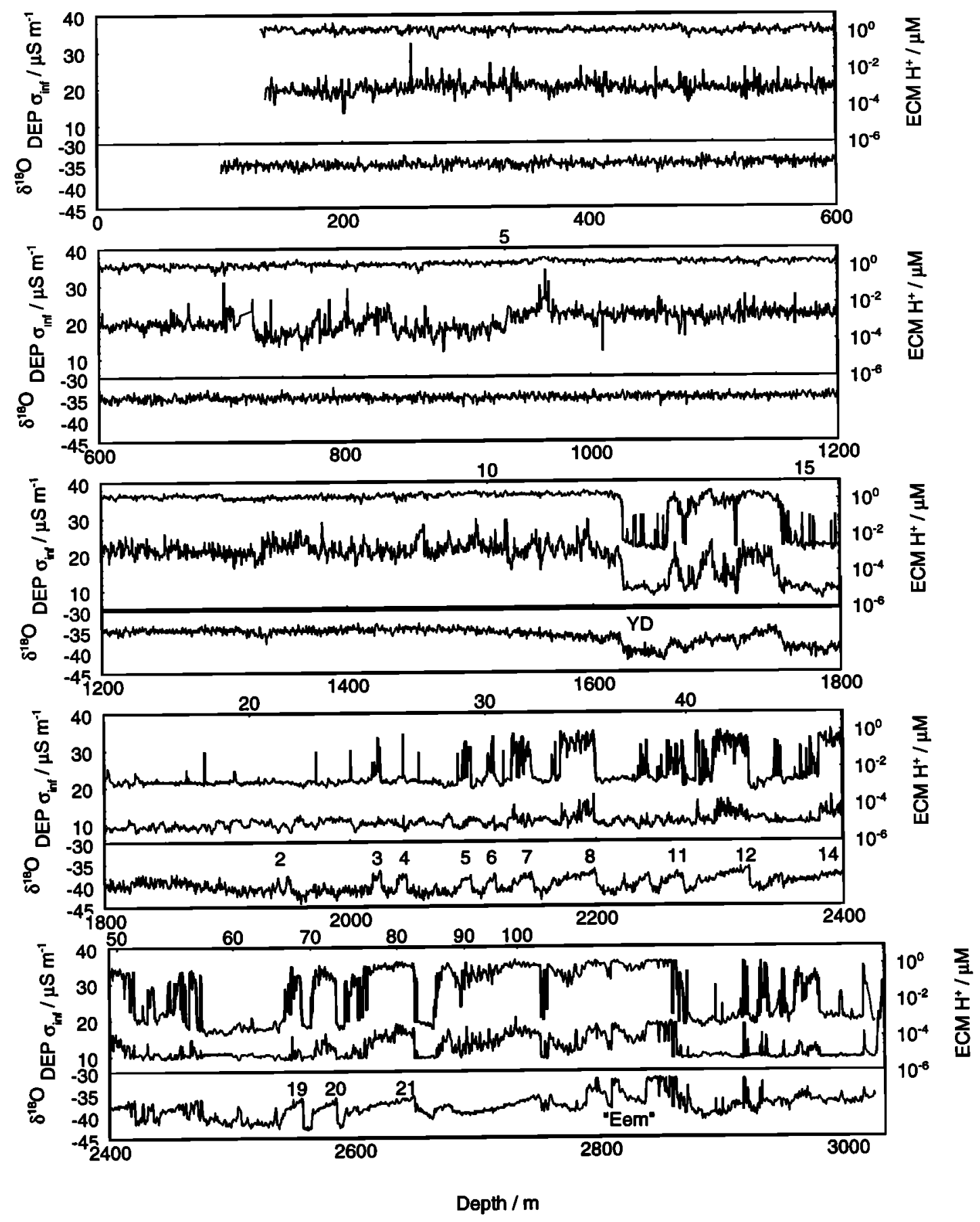

Figure 3. The electrical records (in 55-cm averages) for the entire GRIP ice core, in 600-m sections. The electrical conductivity method (ECM) is the top curve on each larger box and is on a logarithmic scale; dielectric profile (DEP) is the lower curve, and the oxygen isotope signal is shown below each range. The signals are depth, not time, averaged (see Figure 2 caption). The figures given above each plot are dates (in kiloyears B.P.), and the numbers on the oxygen isotope plots refer to some of the interstadials identified in the GRIP core [Dansgaard et al., 1993]. YD, Younger Dryas; Eem, Eemian period.

periods the ice is alkaline. The same result has previously been noted in cores from Dye 3, south Greenland [Hammer et al., 1985], Renland, east Greenland [Johnsen et al., 1992b], and Camp Century, north Greenland [Hammer et al., 1980]. It seems that, in colder periods, any atmospheric acidity present is neutralized by carbonaceous, clay mineral, and terrigenous dusts. This is a very important change in atmospheric composition that presumably occurred over at least a large part of the northern hemisphere (Antarctic ice remains acidic even in cold periods [Hammer et al., 1985]). The detailed form of the relationship between the electrical signals and the oxygen isotope ratio (and with calcium) is discussed later. The warm/cold, acid/alkali balance is the main feature of the ECM profile and is also the main control on the gross changes in the DEP signal, although other factors are also important there.

There are two areas where the data as presented must be 
Table 1. Electrical Characteristics of Different Climatic Periods in the Greenland Ice Core Project

\begin{tabular}{|c|c|c|c|c|}
\hline Period & Depth, $\mathbf{m}$ & $\mathrm{ECM} \mathrm{H}^{+}, \mu M$ & $\mathrm{DEP} \sigma_{\infty}, \mu \mathrm{S} \mathrm{m}^{-1}$ & $\delta^{18} \mathrm{O}, \%$ \\
\hline Holocene & $134-1620$ & $1.56 \pm 0.45(0.37,3.63)$ & $20.5 \pm 2.3(11.8,33.9)$ & $-35.0 \pm 0.8(-38.5,-32.3)$ \\
\hline YD & $1625-1661$ & $0.016 \pm 0.033(0.001,0.132)$ & $10.0 \pm 0.8(8.0,12.4)$ & $-40.6 \pm 0.9(-42.3,-38.3)$ \\
\hline $\mathrm{A} / \mathrm{B}$ & $1663-1752$ & $1.0 \pm 0.7(0.002,3.0)$ & $15.7 \pm 3.6(8.2,23.3)$ & $-37.4 \pm 1.4(-40.9,-34.1)$ \\
\hline Glacial & $1800-2600$ & & & \\
\hline "Cold" $(\delta<-40)$ & & $0.003 \pm 0.018(0.0001,0.38)$ & $10.2 \pm 0.9(7.5,13.7)$ & $-41.3 \pm 0.8(-44.3,-40.0)$ \\
\hline "Warm" ( $\delta>-38)$ & & $0.22 \pm 0.22(0.0006,0.98)$ & $11.5 \pm 2.0(7.8,17.6)$ & $-37.4 \pm 0.5(-35.9,-38)$ \\
\hline $5 e 5(8>-34)$ & $2840-2860$ & $1.4 \pm 0.1(1.1,1.6)$ & $18.3 \pm 0.5(17.0,19.4)$ & $-32.0 \pm 0.4(-31.6,-32.8)$ \\
\hline
\end{tabular}

All data are means, standard deviations, and (in brackets) ranges of the 55-cm averaged data sets. YD, Younger Dryas; A/B, Allerod/Bolling. The electrical conductivity measurement (ECM) and dielectric profiling (DEP) range maxima are after removal of volcanic peaks.

treated cautiously. In the DEP profile, the section from 730 to $930 \mathrm{~m}$ shows great variability and apparent level changes not seen in the ECM. This section of ice was measured at the start of the 1991 season, when the temperature correction was at its largest, and was also most uncertain: it is likely that the apparent level changes result from this. Second, we note that typical 55 $\mathrm{cm}$ average ECM levels recorded in cold period ice above 2300 $m$ depth are $10^{-3} \mathrm{M}$, but below this depth, they drop much lower, down to $10^{-4} M$. While this could be real, the relationship (see later) with oxygen isotopes and with calcium suggest that a step change occurred between the ice measured at the end of 1991 and that measured at the start of 1992 . We note that the temperature correction used has not been tested for alkaline ice, and may be inappropriate; this could partly explain such a discrepancy occurring in the alkaline ice only.

\subsection{Electrical Characteristics of Different Climatic Periods}

3.2.1. Holocene. The Holocene $(0-1623 \mathrm{~m}, 0-11550$ years B.P.) is characterized by a rather stable oxygen isotope ratio and by high acidities represented by high ECM and DEP signals (Table 1). The vast majority of the volcanic signals (removed from the background) occurred in this section or in the Allerod/Bolling period. The detailed (2-cm resolution) record is shown (Figure 4) for two sections of the core where no volcanic peaks were removed (i.e., this is the original unfiltered data). It can be seen that there is a close correspondence between the two electrical records, with good agreement in the position and strength of the peaks and troughs, which are probably mainly annual cycles in acidity. The major acids in Holocene snow at Summit are nitric followed by sulphuric, with nitric acid (peaking in midsummer) being the clearest contributor to the annual cycle in acidity [Herron, 1982; Steffensen, 1988; Whitlow et al., 1992]. Some of the remaining difference between the two records in background sections of the Holocene is due to ammonium, which (except when there are large spikes, see below) has annual cycles of amplitude approximately $1 \mu M$ [Fuhrer et al., 1993]; these are expected to give DEP changes of $1 \mu \mathrm{S} \mathrm{m}^{-1}$. Chloride averages at about $0.35 \mu M$ in the Holocene at Summit [Whitlow et al., 1992] (also $M$. Legrand, personal communication, 1994), and this will give a $\sigma_{-\infty}$ contribution of only $0.2 \mu \mathrm{S} \mathrm{m}^{-1}$.

There are two types of feature where clear differences between the ECM and DEP signals were seen in the Holocene period. The first of these occurred where there were large ammonia peaks, believed to be due to biomass burning [Legrand et al., 1992]. In such peaks, acidity is partly neutralized, or may combine with formate to produce formic acid (a weak acid); this leads to a fall in the ECM current. In contrast, the ammonium gives a rise in the DEP signal [Moore et al., 1994]. This type of feature is illustrated in Figure 5. The second feature occurs where there are visible ash layers in the core. In these cases, much less commonly observed, the high-resolution DEP system [Moore, 1993] reveals a peak coinciding with the position of the visible ash (Figure 6). Presumably, this peak is due to some component of the ash, most likely chloride.

There are no clearly defined trends in the electrical signal (hence acidity) during the Holocene, in line with the very steady oxygen isotope signal. The most significant oxygen isotope feature in the Holocene is at $1334 \mathrm{~m}$ (approximately $8.2 \mathrm{kyr}$,
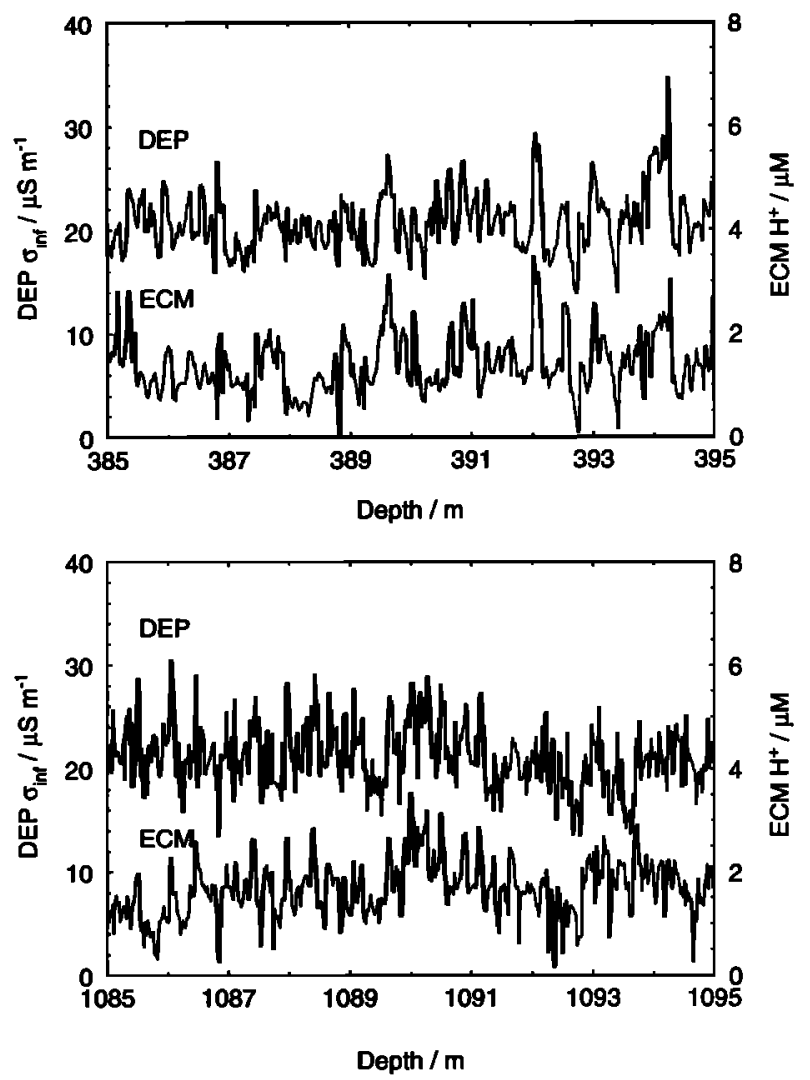

Figure 4. The electrical records (at $2-\mathrm{cm}$ resolution) for two sections of the GRIP core. The 385 to $395 \mathrm{~m}$ section is around 1800 years B.P. with annual layer thicknesses of order $0.20 \mathrm{~m}$; the 1085 to $1095 \mathrm{~m}$ section is around 6100 years B.P. with annual layer thicknesses of order $0.13 \mathrm{~m}$. DEP, dielectric profile; ECM, electrical conductivity measurement. 

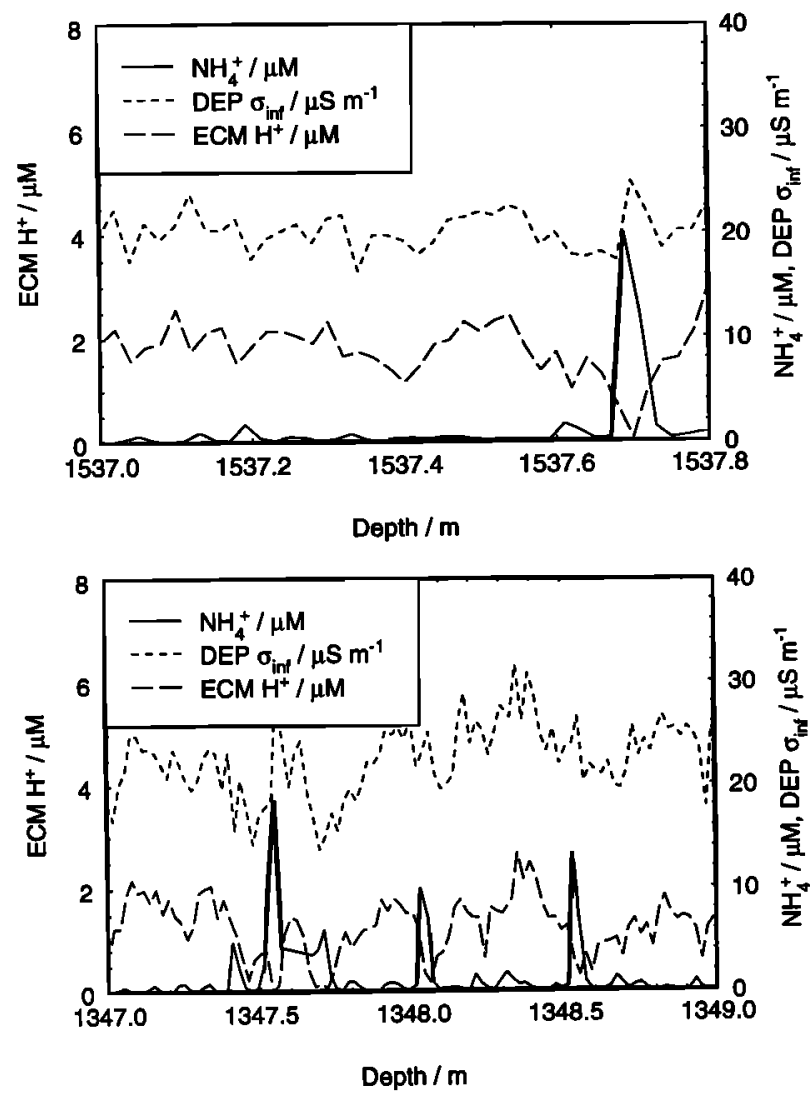

Figure 5. The electrical and ammonium profiles (all at $2-\mathrm{cm}$ resolution, unfiltered) for two Holocene sections of the GRIP core. In both sections large ammonium peaks are accompanied by dielectric profiling (DEP) peaks and electrical conductivity measurements (ECM) troughs.

where the oxygen isotope ratio reaches its lowest $55-\mathrm{cm}$ average value during the Holocene). There is no apparent deviation in the electrical records at this depth, suggesting that the acidity of the atmosphere was unaffected by whatever event was taking place.

3.2.2. Younger Dryas. The Younger Dryas (YD) (1623-1661 $\mathrm{m}$, preliminary dating $11550-12700$ years B.P. [Johnsen et al., 1992a]) was the last sustained period of "cold" oxygen isotope values in Greenland cores. The ECM and DEP signals remained low throughout almost the entire period (the highest YD 55-cm average ECM value is lower than any Holocene value). The atmosphere was alkaline during the YD, as confirmed by the high calcium concentrations that have been measured [Fuhrer et al., 1993; Mayewski et al., 1993]. There are just a few places where the detailed $(2 \mathrm{~cm})$ ECM signal shows an acidic atmosphere: between 1625 and $1660 \mathrm{~m}$ there are four peaks (each just a few centimeters wide) where the ECM signal rises above $1 \mu M$ and a further five where it rises above $0.1 \mu M$. In these cases since Ca shows no decrease, the fact that acidity emerges above the background suggests that volcanic eruptions have been strong enough to overcome the otherwise alkaline atmosphere for perhaps 1 year in each case. When the ECM signal is low, there is still structure in the signal when it is amplified and plotted on a logarithmic scale. This structure appears to be seasonal and to be related to the Ca signal (with even lower ECM when the ice is more alkaline). However, this structure is more easily studied in the yet more alkaline ice of the coldest parts of the glacial period and will not be discussed further in this section.

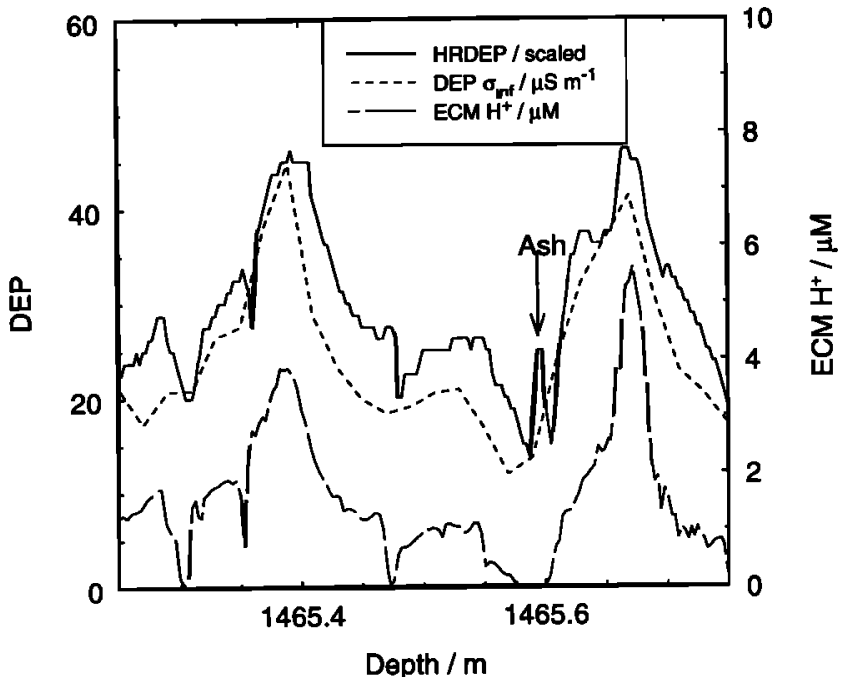

Figure 6. Electrical records around an ash layer at $1465.6 \mathrm{~m}$ depth. The normal dielectric profiling (DEP) record is at 2-cm resolution, unfiltered. The high-resolution DEP (HRDEP) signal is at $2.5 \mathrm{~mm}$ resolution, is scaled to arbitrary units, and shows a peak across the ash layer. The electrical conductivity measurement $(E C M)$ is shown at its original (approximately 3 $\mathrm{mm}$ ) resolution.

The DEP signal shows peaks at the few places where the $\mathrm{ECM}$ is higher. Apart from that, the signal is very closely related to the ammonium signal in the YD (Figure 7), as previously noted [Moore et al., 1994]. Ammonium is actually at its highest in the YD, and the signals probably include a seasonal cycle and larger peaks that have been ascribed to biomass burning episodes [Legrand et al., 1992].

The rapidity of change at the start and end of the YD has been a cause of considerable discussion [Taylor et al., 1993b]. The electrical signals (acidity) do indeed change very rapidly

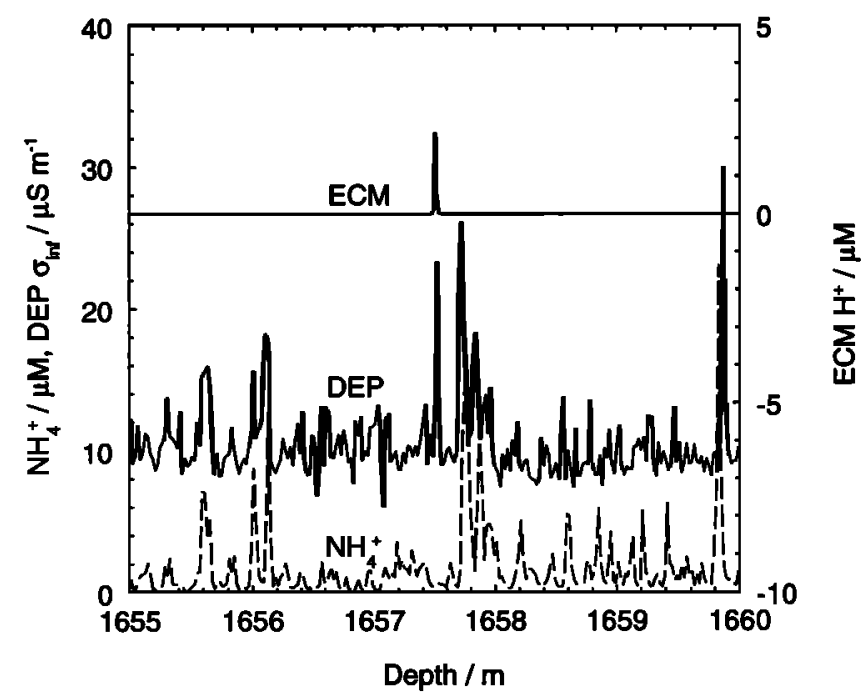

Figure 7. Electrical and ammonium records in a section of the Younger Dryas ice. Apart from the peak corresponding to the electrical conductivity measurement (ECM) peak at $1657.5 \mathrm{~m}$, the dielectric profiling (DEP) signal corresponds closely to the ammonium record (allowing for up to approximately $2 \mathrm{~cm}$ depth mismatches). 

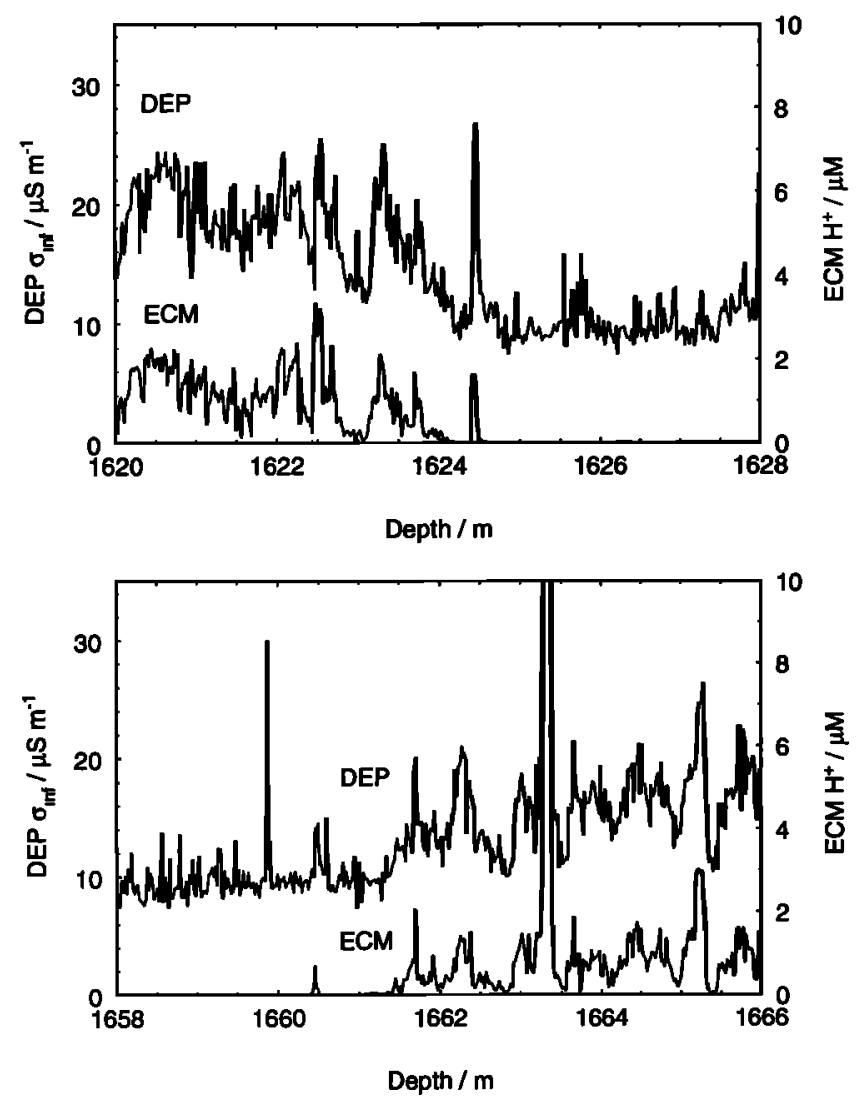

Figure 8. Electrical records (2-cm resolution) at the (top) start and (bottom) end of the Younger Dryas period. Note that the large dielectric profiling (DEP) peak at $1659.8 \mathrm{~m}$ (as well as some smaller ones) is due to ammonium. ECM, electrical conductivity measurement.

(Figure 8) (complete transitions in decades, with still faster changes previously described as "flickers" [Taylor et al., 1993b]), although the pattern of change is not identical to that seen in the GISP2 core on subdecadal timescales. However, we urge some caution in discussing the timescale of changes and climate "flickers" on the basis of the electrical records alone. To neutralize typical Holocene levels of acidity requires only about $1 \mu M$ of $\mathrm{CaCO}_{3}$. During the YD, Ca is typically $4 \mu M$ and higher still in much of the cold glacial period ice [Fuhrer et al., 1993]. Changes in acidity of the ice are reflecting mainly the neutralization process, that is changes in alkaline dust levels in the atmosphere. The more or less complete reduction of the electrical signals will, however, be accomplished when the dust (or $\mathrm{Ca}$ ) has risen to only $25 \%$ of its YD value. In this sense the electrical records at the transitions give a highly nonlinear version of the dust changes. As an example of this, at the end of the YD (YD/preboreal transition), the most obvious and sharp fall in the Ca level (50\% reduction in about $6 \mathrm{~cm}$, approximately 1 year) occurs at $1624.3 \mathrm{~m}$ [Fuhrer et al., 1993], but the general level of the electrical signals barely alters there because the ice is still alkaline. Above that depth, relatively minor reversals in the continuing $\mathrm{Ca}$ reduction are seen as quite large apparent "flickers" in the electrical record. In summary, the electrical records cannot easily be used to indicate the rate or style of change of their primary determinant, atmospheric dust (and ultimately probably atmospheric circulation). However, the electrical records do probably give a genuine indication of the rate of change of atmospheric acidity; this would affect the type of aerosol present (relevant to radiation and cloud formation issues, discussed later) and, (if similarly reflected in vegetated regions) the acidity changes would be an important factor determining ecological stress.

3.2.3. Allerod/Bolling period. The Allerod/Bolling (A/B) interstadial (1661-1753 m, 12700-14450 years B.P.) saw rather warm oxygen isotope values (Table 1), with two major cold excursions [Johnsen et al., 1992a]. Most Ca values are in the range 0.4-1.0 $\mu M$. This is just the range needed to neutralize typical Holocene-type acidities and, as a result, the acid-alkali balance is very finely weighted, and the ECM and DEP signals change quite frequently from high to low values, as already noted in the GISP2 core [Taylor et al., 1993b]. However, we again emphasize that this reflects the nonlinear relationship between acidity and changes in alkaline dust content, so that relatively small $\mathrm{Ca}$ changes appear as complete electrical transitions. However, the ice remains acidic, or nearly so, through the $A / B$, so that there are many large volcanic peaks (filtered out of Figures 2 and 3). Through much of the period, ECM and HRDEP records show a seasonal variation that can be used for dating (at 2-cm resolution in the normal DEP, annual dating is no longer possible). However, this needs to be done with care: in the Holocene, the seasonal variation in ECM is due solely to the seasonal input of acid, and it is reasonable to imagine that this gives one peak per year. In the $\mathbf{A} / \mathrm{B}$, the seasonal variation is somewhat similar, but occasionally the alkaline material may also control the seasonality. The acid, dust, or both, may be the chief influence at any given time in the $\mathrm{A} / \mathrm{B}$, leading to changes in the ECM seasonality, and to the possibility of double peaks or troughs. The use of other parameters (dust, nitrate, ammonium) should clarify the annual layer identification.

Overall, the ECM signal follows (inversely) the shape of the Ca record very well in the $A / B$, but with additional peaks from volcanic input. The DEP also follows ECM very closely, but with a few further peaks from ammonium spikes. These are clearer in the late $\mathrm{A} / \mathrm{B}$, when ammonium is higher [Fuhrer et al., 1993] and acidity is lower (because Ca and mineral dust content are higher). While the acidity record is so dominated by neutralization from alkaline dusts, it may be possible to deduce

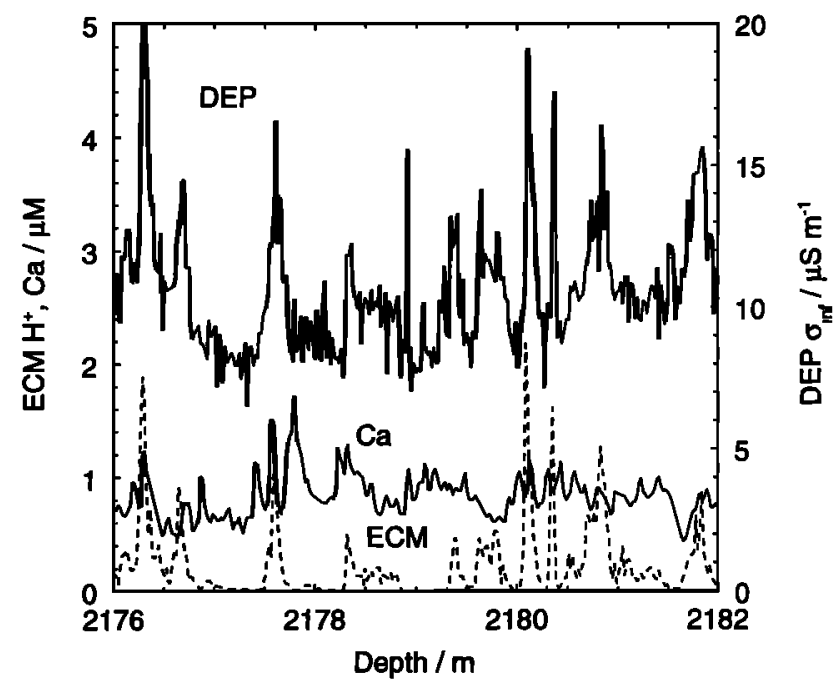

Figure 9. Electrical and Ca records (2-cm resolution) for a part of interstadial 8. ECM, electrical conductivity measurement; DEP, dielectric profile. 
something about the amount of acid originally input to the atmosphere, and this will be investigated in a later section.

3.2.4. The last glacial. In this section, we discuss the last glacial, down as far as the bottom of the interstadial identified as IS20 [Dansgaard et al., 1993], that is, to $2590 \mathrm{~m}, 74 \mathrm{kyr}$ B.P. This period is characterized by extremely cold conditions, punctuated by a series of warmer interstadials (the DansgaardOeschger events).

Both the ECM and DEP signals are generally low during this period (Figure 3), rising (but never to Holocene or A/B levels) during some of the interstadials. This reflects the alkaline nature of most of the ice, confirmed by moderate to very high (more than $20 \mu M$ in some cold sections) Ca levels [Fuhrer et al., 1993; GRIP Project Members, 1993].

There are 14 peaks that rise above the ECM $4 \mu M$ threshold for filtering in this $60 \mathrm{kyr}$ period: each is only $2-6 \mathrm{~cm}$ wide, and all but one occur during warm interstadials, when $\mathrm{Ca}$ and dust levels are lower. It must be remembered that the criterion for seeing volcanic peaks in this section is harsher not only because much of the ice is alkaline, but also because the annual layer thickness varies from about $5 \mathrm{~cm}$ just below the $A / B$ to $4 \mathrm{~mm}$ in the colder sections just above $2600 \mathrm{~m}$. To be visible in a $2-\mathrm{cm}$ increment, a 1-year volcanic peak must be much larger than further up the core. The most obvious feature of this section is the contrast between the cold (low $\delta^{18} \mathrm{O}$ ) ice, with continual low electrical signals, and the warm (interstadial ice) which contains some ice with higher electrical signals. It is simplest to consider these types of ice separately.

In the interstadials, the electrical signals are sometimes higher, typical of somewhat acidic ice, but the signal within the interstadials is very variable (Figure 3). The most important determinant is certainly the Ca [Fuhrer et al., 1993; GRIP Project Members, 1993] (and to some extent mineral dust) concentration. The ice is acidic only when $\mathrm{Ca}$ is about $1 \mu M$ or lower. Therefore there is very little response in interstadials 2-4 (around 1950, 2020, $2040 \mathrm{~m}$ ) because Ca stays above this threshold. In earlier interstadials, Ca falls to progressively lower values, and the ice becomes more, or more consistently, acidic. However lower $\mathrm{Ca}$ is a necessary but not a sufficient condition for acidic ice, as exemplified by Figure 9. The Ca level of about 0.6-1.0 $\mu M$ (still far higher than Holocene $\mathrm{Ca}$ levels) is in the right range to just neutralize typical Holocene levels of acidity. However, the acidity record within this range is not clearly

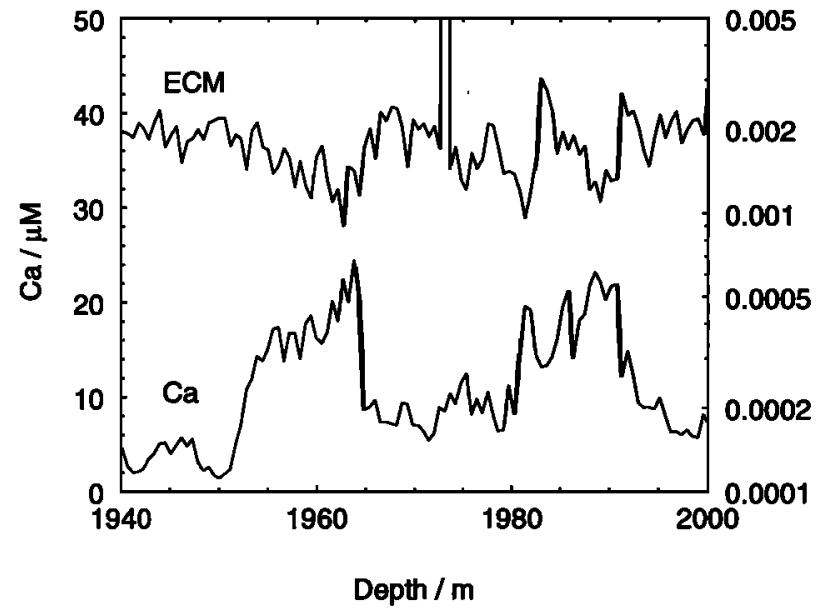

Figure 10. Electrical conductivity measurement (ECM) and $\mathrm{Ca}$ records (55-cm averages) for part of the last glacial maximum.

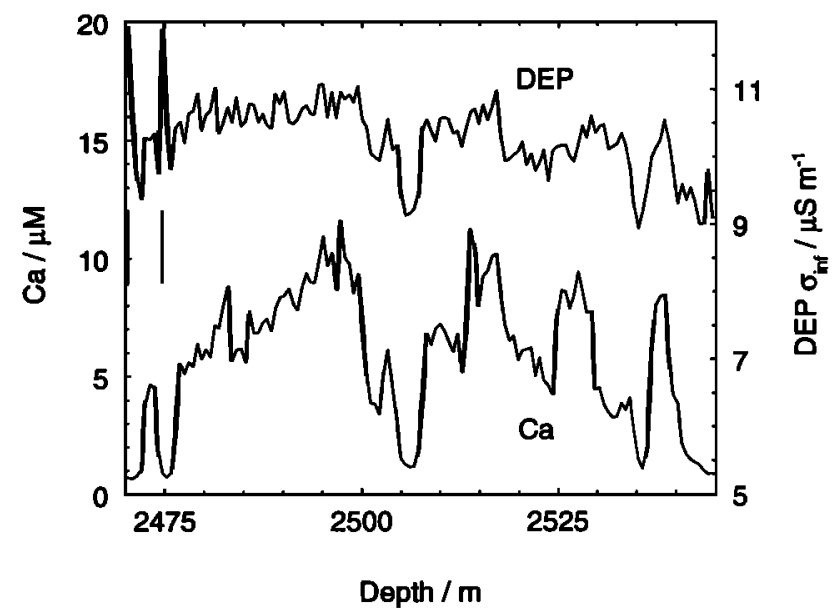

Figure 11. Dielectric profiling (DEP) and Ca records for part of the early glacial period. The two vertical lines at 2470 and 2475 $\mathrm{m}$ are the position of electrical conductivity measurement (acid) peaks.

related to $\mathrm{Ca}$ and is likely a complex result of $\mathrm{Ca}$, dust, and acidity source changes. These changes within the interstadial are not related to any apparent change in the isotopic climate signal, and the term "climate flickers" should not be applied to them.

In the interstadials, ECM and DEP are very closely related. Ammonium is mainly in the range 0.2-0.5 $\mu M$ throughout the glacial period and will have little influence on the DEP signal.

In the cold parts of the glacial, the electrical signals stay uniformly low (Table 1). However, there are significant variations even within these periods. In general, the very low ECM signal falls still further as Ca becomes yet higher (i.e., as the ice becomes more alkaline). This is shown in Figure 10, where the ECM signal is of the order 0.002-0.003 $\mu M$ when $\mathrm{Ca}$ is in the range 1-6 $\mu M$ but falls toward $0.001 \mu M$ as $\mathrm{Ca}$ rises above $20 \mu M$. The ECM units here are rather arbitrary, as the ice is alkaline, and the meaning of the residual current in terms of conduction mechanisms and chemical species present is not known (the fall from 0.002 to 0.001 in these units represents a drop in the measured current from $0.26 \mu \mathrm{A}$ to $0.18 \mu \mathrm{A}$ ).

It is harder to see remaining variations in the DEP signal, as variations during the cold periods are at most about $2 \mu \mathrm{S} \mathrm{m}^{-1}$ on a background of $9 \mu \mathrm{S} \mathrm{m} \mathrm{m}^{-1}$. In the sections of ice measured in 1991, the problems of temperature correction described earlier tend to mask any meaningful variations, although there is a hint of higher signals in places where the ice has a higher impurity content (as represented by $\mathrm{Ca}$ ). This is seen more clearly in the ice measured in 1992, and in Figure 11. The DEP signal here has an underlying relationship with $\mathrm{Ca}$ content, with higher values when $\mathrm{Ca}$ is higher (and therefore an anticorrelation with the ECM signal in this section of core). Both acidity and ammonium are low in this part of the core. The only remaining impurity that we know causes DEP signals is $\mathrm{Cl}^{-}$[Moore et al., $1992 a, b]$.

The largest peak to trough variations in DEP are about $1.5 \mu \mathrm{S}$ $\mathrm{m}^{-1}$ and would represent a change of about $3 \mu M$ in $\mathrm{Cl}^{-}$. The range of $\mathrm{Cl}^{-}$concentrations in this region is of the right order, at 1-3 $\mu M$, with the higher values generally where $\mathrm{Ca}$ is higher. However, there are insufficient $\mathrm{Cl}^{-}$data available (one section measured every $11 \mathrm{~m}$ ) at this point to show whether it is responsible for the remaining DEP signal, and further, highresolution sampling will be necessary to achieve this. The 

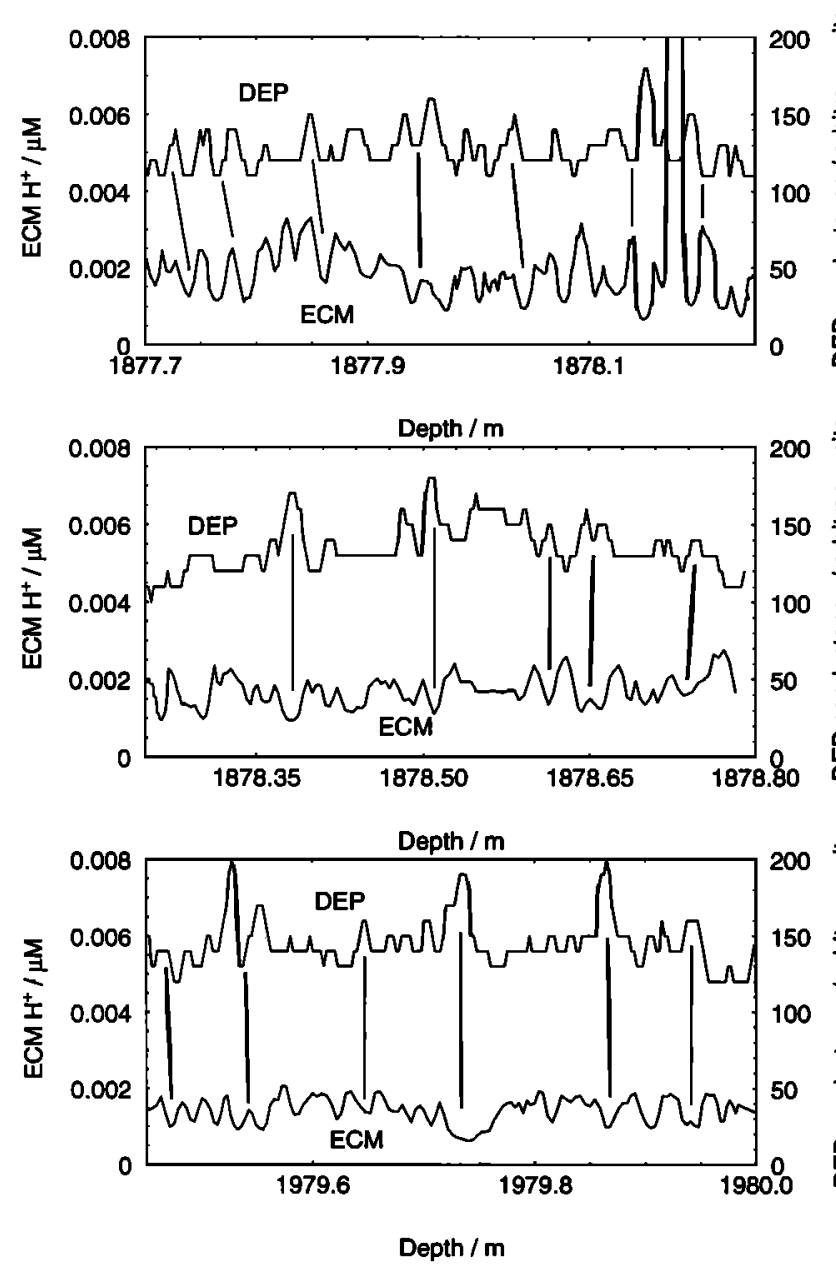

Figure 12. High resolution dielectric profiling (HRDEP) and electrical conductivity measurement (ECM) records (2-mm resolution) for three sections of glacial ice. The ECM depths for each core section were shifted a constant amount $(0 \mathrm{~cm},-2 \mathrm{~cm}$, $-1 \mathrm{~cm}$ in the three cases) to give the most reasonable fit. The near-vertical lines show assigned matches between the records.

anticorrelation between ECM and DEP signals in the cold, alkaline ice, is also seen at high resolution from comparisons of the ECM and HRDEP signal (Figure 12). It is difficult to do such comparisons, because although both methods have a resolution of order $2 \mathrm{~mm}$, they also both have an uncertainty in the position along the core of order $1 \mathrm{~cm}$. However, in some clear cases, this can be corrected by making a shift using clear features, and there is less uncertainty within a core length. Figure 12 shows three sections of core, with assigned matches between peaks in one record and troughs in another. The poor resolution in conductance in the HRDEP was somewhat improved in ice measured from greater depth. The matches could be assigned in a number of ways. However, detailed inspection of peak and trough widths and shapes gives high confidence in our assignment, and the matches are consistent across core lengths (i.e., with no jumps in depth shift required). The anticorrelation assignment was also confirmed by the observation made in the field that prominent cloudy bands (associated with high $\mathrm{Ca}$ and dust levels) were located at HRDEP peaks and at ECM troughs (e.g., there was a prominent $1-\mathrm{cm}$ yellow band at $1979.74 \mathrm{~cm}$ ).
3.2.5. Stages 5a-5d. The section of core from about 2590 (74 kyr) to $2790 \mathrm{~m}$ (114 kyr on the GRIP timescale) represents Stages 5a-d [Dansgaard et al., 1993]. The climatic record of this period is characterized by two further wide, sawtooth-shaped warmings (approximately 2600-2650 $\mathrm{m}$ (labelled as 5a [Dansgaard et al., 1993]), and approx 2700-2750 $\mathrm{m}$ (5c)). The electrical records (Figures 3 and 13) show a similar pattern, with acidic ice in the warm periods and alkaline ice in the colder parts. However, the electrical profiles have a rather squarer shape than does the isotope profile, with some acidic ice throughout the cooling limb of 5a and 5c, and sustained lower signals only above $2590 \mathrm{~m}$, from 2650 to $2670 \mathrm{~m}$, and in the brief reversal just below $2750 \mathrm{~m}$. This is similar to the $\mathrm{Ca}$ signal, which rises significantly above $1 \mu M$ only during these depth intervals. In the warm periods, the ECM and DEP signals are very well correlated, and reach $A / B$ type values, but not Holocene ones. In the colder period from 2670 to $2650 \mathrm{~m}$, it can be noted that, as the $\delta^{18} \mathrm{O}$ value rises (and the high $\mathrm{Ca}$ concentration falls), ECM values rise, while DEP values fall slightly. This again illustrates the anticorrelation seen in the coldest, most alkaline period of the glacial. Finally, ammonium concentrations reach $55 \mathrm{~cm}$ averages of about $1 \mu M$ at the start of 5a and 5c: individual peaks at higher resolution of up to $4 \mu M$ are large enough to cause narrow drops in the ECM signal, but not large enough to raise the DEP signal, as occasionally happened in the Holocene and in cold-period ice.

3.2.6. "Eemian" ice. The ice between 2790 and $2880 \mathrm{~m}$ has been considered to represent ice from the last (Eemian) interglacial (stage 5e) [GRIP Project Members, 1993], but discrepancies between the GRIP and GISP2 core at this depth have called this interpretation into question. The characteristics of this section have been extensively described [GRIP Project Members, 1993]: it consists of isotopically very warm ice, interspersed with colder ice, with particularly rapid changes between the two types, especially at the start of the sequence. Both the DEP and ECM records follow the isotopic signal very closely (Figure 3), with acidic ice in the warm sections, alkaline ice in the cold. This is illustrated for the start of the period in

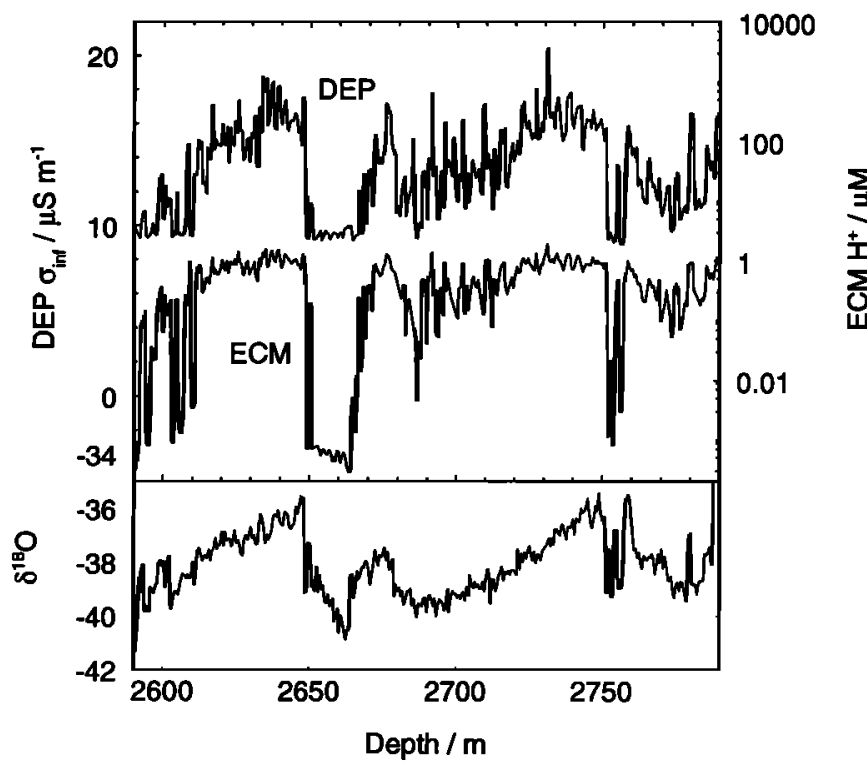

Figure 13. Electrical and isotope records $(55 \mathrm{~cm}$ resolution) for the section of core identified as stages 5a-d. ECM, electrical conductivity measurement; DEP, dielectric profile. 


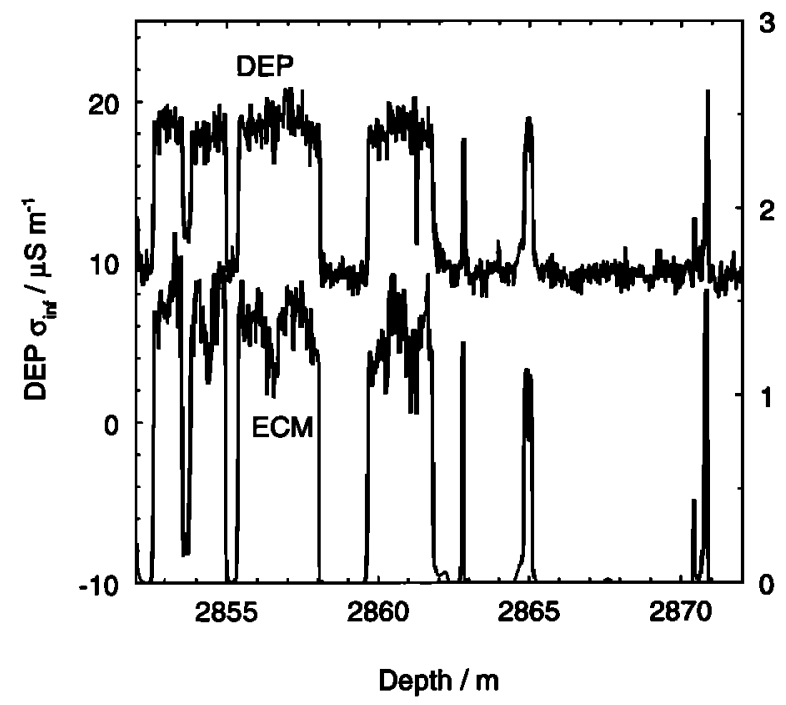

Figure 14. Electrical records (2-cm resolution) for the start of the "Eemian" section of ice. ECM, electrical conductivity measurement; DEP, dielectric profile.

Figure 14. The many sharp transitions tend to emphasize this relationship, which also holds for the relationship with $\mathrm{Ca}$, as we would expect. Within each cold period in the Eemian, as for cold periods in the glacial, the small ECM signal tends to be anticorrelated with the DEP variations (not illustrated).

Although oxygen isotope ratios are higher than in the Holocene, neither ECM or DEP signals quite reach Holocene values for any sustained period. This could mean that atmospheric acidity was indeed lower in this period than in the Holocene, or that the electrical signal for a given acidity is lower in this aged ice. In fact, we have found that nitrate, the main counteranion, also has lower concentrations in this period than in the Holocene, so it seems that the first explanation is probably correct: acidity was lower in the warm Eemian than in the Holocene.

3.2.7. Pre-"Eemian" ice. From $2880 \mathrm{~m}$ to $3020 \mathrm{~m}$, the isotope signal is variable, though with something of a rising trend toward the bed. The ECM and DEP signals also show variations, parallel with each other, and related to the isotopic changes. However, the signals suggest that most of this ice is alkaline.

\section{Comparisons Between Data Sets}

We now investigate (using $55-\mathrm{cm}$ averaged data) the relationship between the electrical records and other parameters, and the way in which these may vary from one climatic period to another.

\subsection{Comparison of the Two Electrical Records}

The relationship over the whole data set $(55 \mathrm{~cm}$ averages) between the DEP and ECM signal is shown in Figure 15. The general form described throughout the text is apparent, with quite a narrow band encompassing all data. At the acidic end of the relationship, a linear plot (Figure 16) has a lower bound with a gradient of about $4 \mathrm{~S} \mathrm{~m}^{-1} M^{-1}$, as predicted from previous considerations (equation (2)). The scatter is partly measurement noise, and partly reflects the other contributors (especially ammonium) to the DEP signal. The DEP signal increases again in the most alkaline ice (Figure 15), as already discussed in the

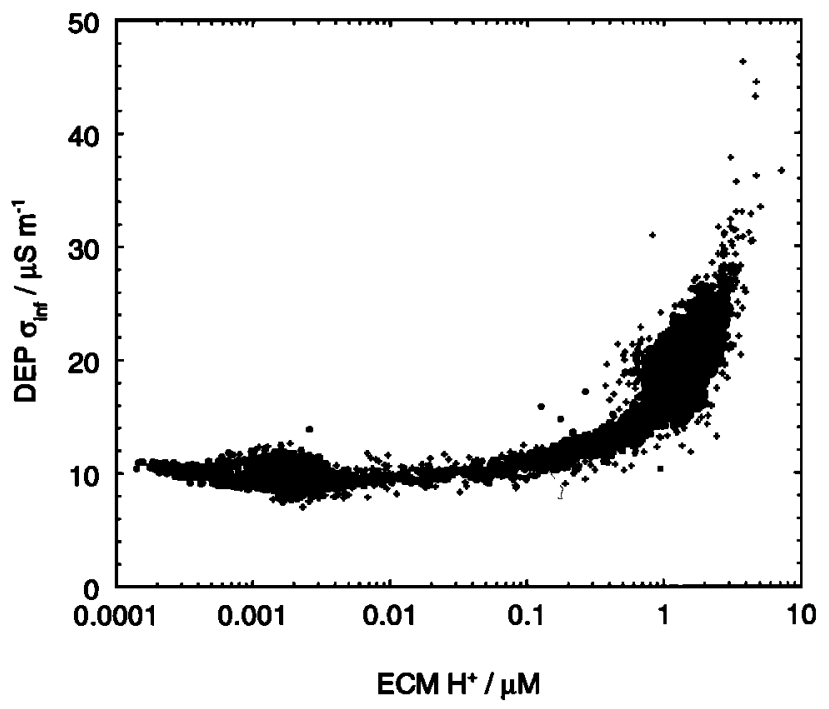

Figure 15. The relationship between the dielectric profiling (DEP) and electrical conductivity measurement (ECM) (on log scale) signals (55-cm averages). Pluses are for data above 2300 $\mathrm{m}$, solid circles are data below $2300 \mathrm{~m}$.

sections on the detailed data. This is likely due to increased chloride concentrations in the alkaline ice. There is more scatter in the data above $2300 \mathrm{~m}$, than in that below, probably reflecting the improved DEP temperature correction below $2300 \mathrm{~m}$. The bulge in the data between 0.001 and 0.005 on the ECM scale may partly reflect the uncertainty referred to in section 3.1 , where the ECM gave signals generally above $0.001 \mu M$ in the data from the earlier years (above $2300 \mathrm{~m}$ ).

\subsection{Relationship of Electrical Records and the Oxygen Isotope Climate Signal}

The oxygen isotope signal is considered the primary climate signal in ice cores and is generally equated to atmospheric temperature. The relationship between the electrical signals and the isotope signal is therefore important, although the relationship

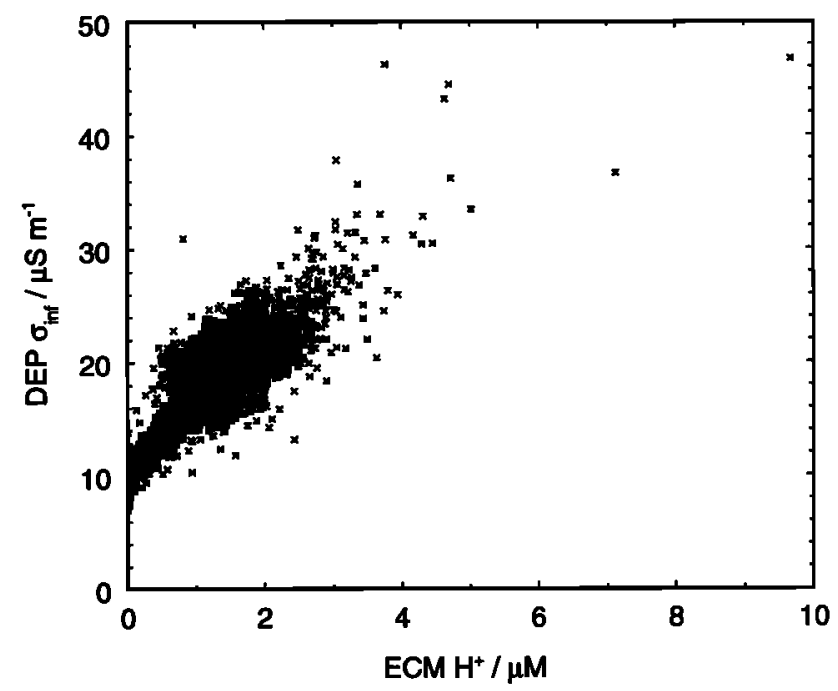

Figure 16. The relationship between the dielectric profiling (DEP) and electrical conductivity measurement (ECM) signals at the acidic end of the scale. 


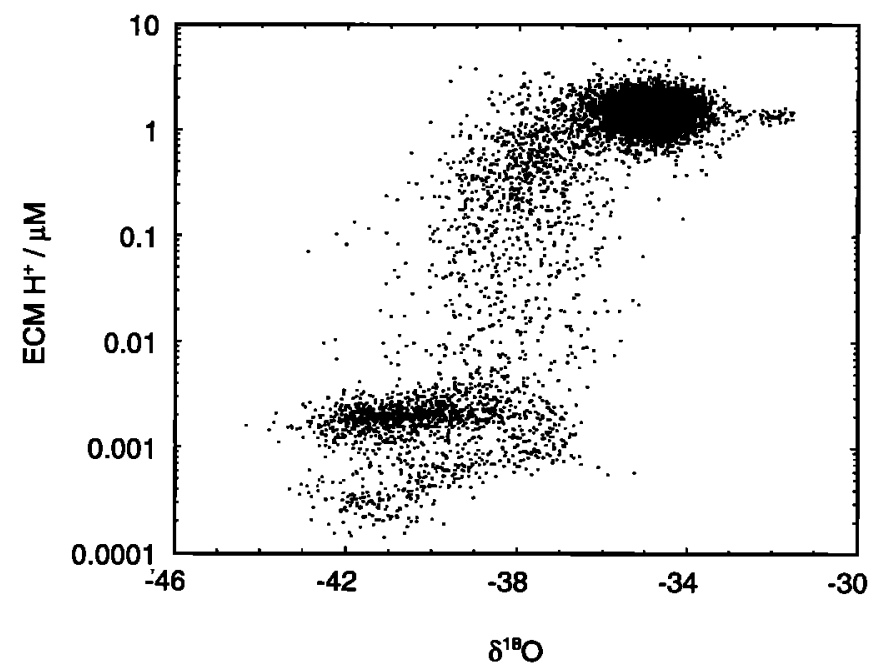

Figure 17. The relationship between electrical conductivity measurement (ECM) signal and oxygen isotope ratio through the whole GRIP core.

with alkaline dust or $\mathrm{Ca}$ is expected to be more direct.

The features seen are generally those expected from the detailed records discussed earlier. The ECM signal (Figure 17) shows two clear regimes. In isotopically "warm" ice, the ECM signal is high because the ice is acidic. There is no apparent trend in ECM signal (acidity) within the "warm" ice (isotope ratio above $-37 \%$ ).

The only exception to this is in the ice between about 2780 and 2880 ("Eemian" ice). In this section, ice with oxygen isotope ratio above $-34 \%$ has a reasonably constant ECM signal (about $1.3 \mu M$ ); ice with oxygen isotope ratio below $-38 \%$ has a low ECM signal $(<0.1 \mu M)$; between these values, the ECM signal falls on a straight line when plotted (linear plot) against oxygen isotope ratio. This could be explained by simple mixing of two components: that is, if the intermediate $55 \mathrm{~cm}$ sections consist of a mixture of "warm" acidic ice, and "cold" alkaline ice, and they sit on a mixing line. In the general plot (Figure 17), there is a precipitous fall in ECM signal, as the ice becomes

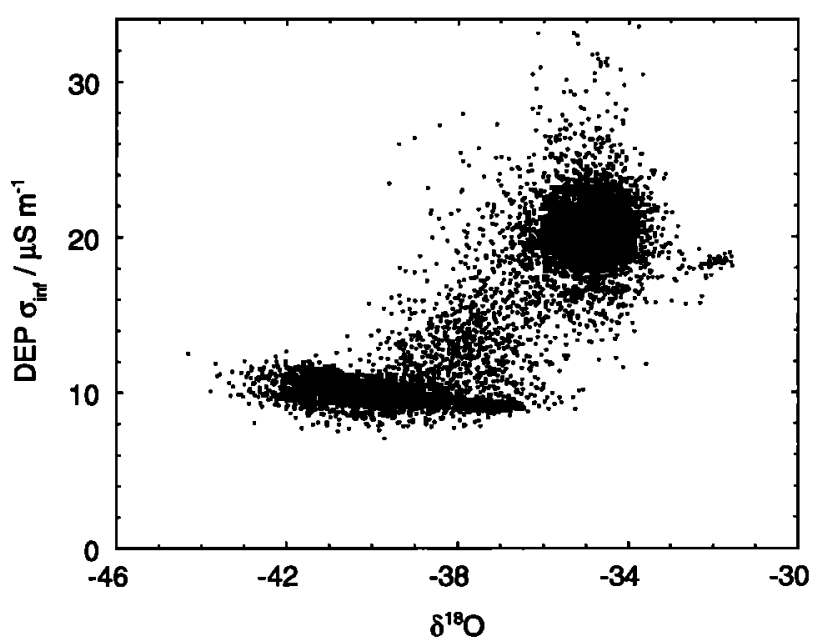

Figure 18. The relationship between the dielectric profiling (DEP) signal and oxygen isotope ratio through the whole GRIP core. Eight data points with a DEP signal $>34 \mu \mathrm{S} \mathrm{m}^{-1}$ are not shown. isotopically "colder." Within the "cold" ice, the signal falls as the oxygen isotope ratio falls still further (i.e., as the ice becomes more alkaline). There are actually two populations in this section: the ice measured in 1992 falls on one line with a steeper gradient leading to ECM values as low as 0.0001 , while the ice measured in earlier years shows a shallower (but still significant) gradient; this reflects the difference in the ECM response discussed in section 3.1.

The DEP signal (Figure 18) also shows two regimes. There are again no trends in the high-DEP, high-oxygen isotope ratio ice. Again, some of the "Eemian" ice falls on a mixing line between high DEP ice with oxygen isotope ratio above $-34 \%$ and low DEP ice with oxygen isotope ratio below $-38 \%$. The isotopically cold ice falls on a single line, with higher values as the isotope ratio falls (i.e. as the ice becomes more alkaline, the DEP signal rises). From the detailed profiles, we suggested this is due to higher $\mathrm{Cl}^{-}$concentrations in this ice.

\subsection{Relationship Between Electrical Signals and Ca Concentrations}

The relationship between the electrical signals and $\mathrm{Ca}$ is fairly simple (Figures 19 and 20). When $\mathrm{Ca}>$ approximately $1 \mu \mathrm{M}$, then acidity is effectively zero, and the ECM signal is very low. The ECM signal falls further as $\mathrm{Ca}$ rises (ice becomes more alkaline), and there are two curves, depending on which year the

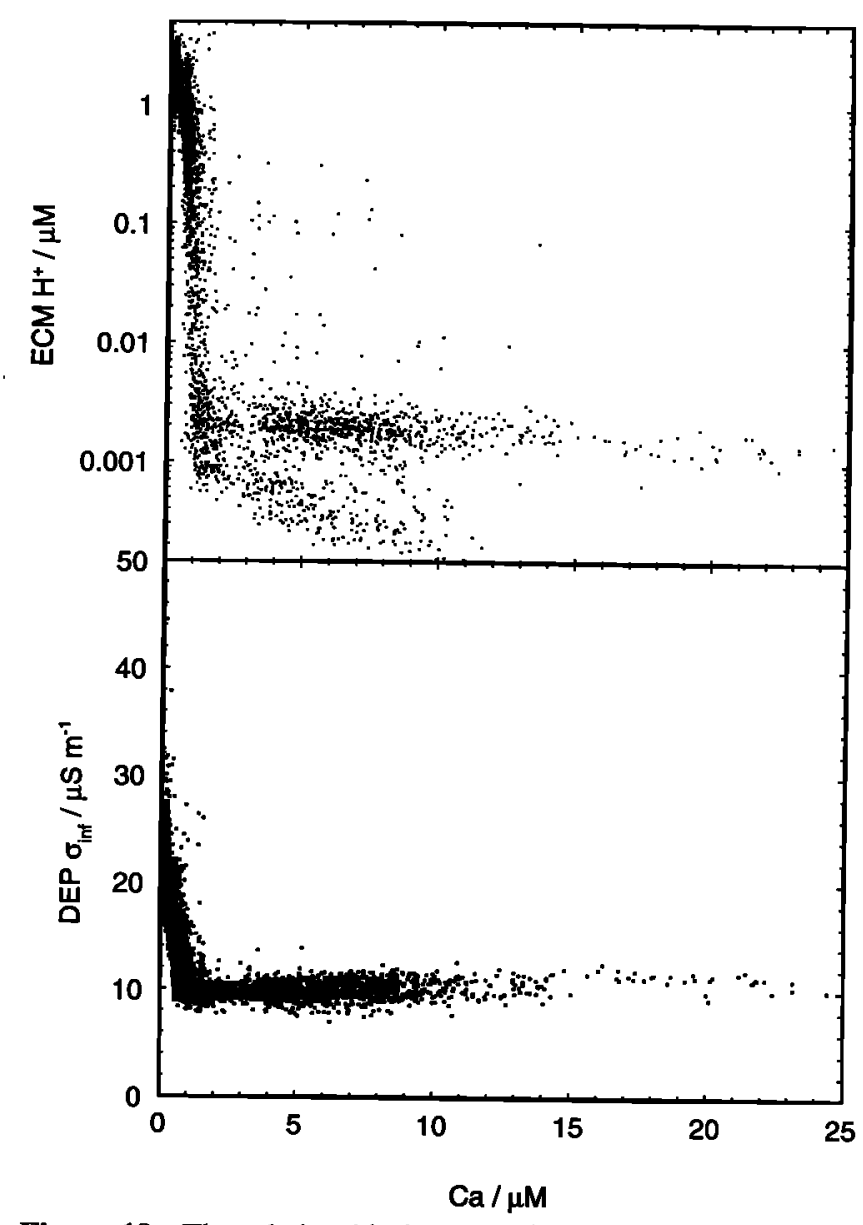

Figure 19. The relationship between the electrical records and $\mathrm{Ca}$ over the entire core from $1300 \mathrm{~m}$ downward (Ca data start only at $1300 \mathrm{~m}$ ). ECM, electrical conductivity measurement; DEP, dielectric profile. 


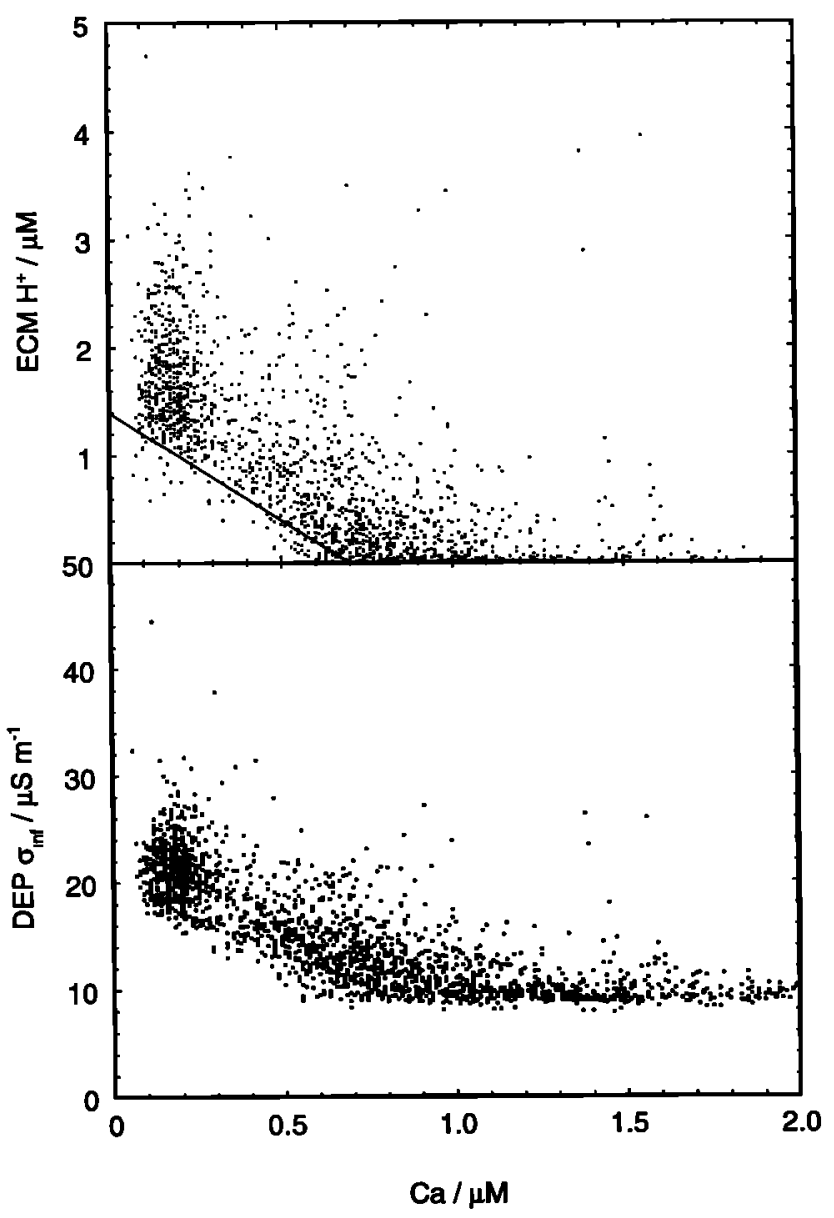

Figure 20. As Figure 19, for $\mathrm{Ca}<2 \mu \mathrm{M}$ only

measurements were made. This was all predicted from the detailed investigations already discussed. The DEP signal rises slightly as $\mathrm{Ca}$ rises, but the few points suggest that the relationship holds only until $\mathrm{Ca}$ is approximately $10 \mu M$; beyond this, the DEP signal is approximately constant. This finding would confirm that it is not Ca directly that causes the DEP increase, but something which is linked to Ca concentrations.

At low Ca concentrations, a good linear relationship between both ECM and DEP, and Ca, is seen. For the ECM signal, the slope of the envelope around the data is very close to 2, as would be expected for neutralization of acid by $\mathrm{CaCO}_{3}$ (Figure 20). In a more dusty atmosphere, neutralization of atmospheric acidity might take place near the sources, during transport to Greenland, or in the ice itself. In the first situation, there would be depletion of the reservoir of acid from which the part transported to Greenland is drawn. There will be major differences between acids and dust in factors affecting their entrainment into air masses transported to Greenland, so that a stoichimetric reaction at the source will not be preserved in the transported air. We would expect the observed stoichimetric relationship only if neutralization occurred en route to Greenland in internally mixed aerosol or air masses, or in the ice itself after separate transport of acid aerosol and dust.

This discussion implicitly assumes that the acidity seen in the ice reflects the acidity of the atmosphere in a linear way. At present, there is uncertainty about this relationship, especially for nitric acid, for which postdepositional losses seem to occur [Wolff, 1995]. If we ignore these problems, then we can use the relationship between acidity and $\mathrm{Ca}$ to calculate a background acidity at times when the acid is partially neutralized. This was done by calculating, for all ice which remains just slightly acidic $\left(\mathrm{ECM} \mathrm{H} \mathrm{H}^{+}>0.1 \mu M\right)$, the sum of $\mathrm{H}^{+}+2 \mathrm{Ca}$. This extends knowledge of the background acidity into the interstadial parts of the last glacial. It can be seen that the background before neutralization remains fairly constant with time (Figure 21), with a slight reduction in corrected acidity in the earliest part of the record. This suggests that, at times when the ice is within this neutral to acidic regime, the factors controlling the concentrations of acid in Greenland snow (some combination of sources, transport, uptake and loss) have not altered very much over the period covered by the core. Caution is needed in interpreting this result, as we cannot at present be certain that the atmospheric concentration is the main determinant of the snow concentration, at least for nitric acid.

\subsection{Further Electrical-Chemical Relationships}

Because a number of chemical components increase more or less in phase with $\mathrm{Ca}$, strong relationships between DEP and a number of other species (e.g., $\mathrm{Cl}^{-}, \mathrm{SO}_{4}{ }^{2-}$ ) could be derived. However, there are relatively few chemical data, and it is difficult to choose which gives the best relationship. Previous work suggests that $\mathrm{Cl}^{-}$is likely to be the relevant species. Choosing only the data where other factors are least likely to add noise to the data (the data from below $2300 \mathrm{~m}$, and where the ice is alkaline), DEP data (corrected for the ammonium signal) do show a positive relationship with $\mathrm{Cl}$, and with a gradient close to that predicted. However, this relationship was defined by only 43 data points, with a $\mathrm{Cl}^{-}$range for all but one point of only just over $2 \mu M$. At high-resolution (subannual), the different chemical components show separate trends, and some initial chemical analyses at this resolution confirm that $\mathrm{Cl}^{-}$is probably the component controlling the DEP signal in this ice with low acid and ammonium content. Although far more data are needed to confirm this, it seems probable that DEP is capable of giving a rapid indication of trends in chloride input. The DEP signal will need to be well corrected for temperature and electrode

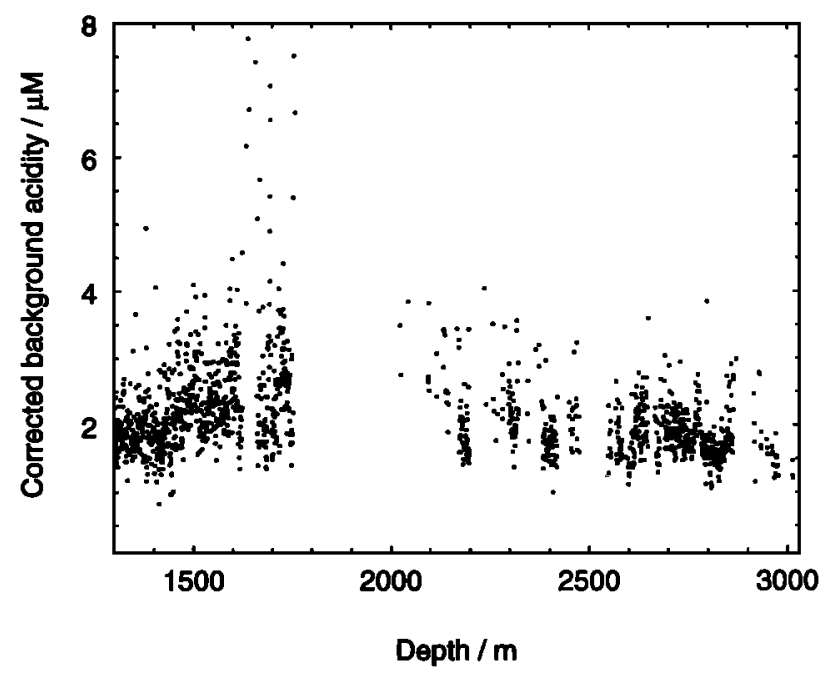

Figure 21. The electrical conductivity measurement (ECM) acidity profile, corrected when $>0.1 \mu M$ by adding twice the $\mathrm{Ca}$ concentration (in micromolar) to it. Data where acidity is $<0.1$ $\mu M$, and 6 data points with corrected acidity $>8 \mu M$, are not shown. 
characteristics (as here for the data below $2300 \mathrm{~m}$ ), and will be of most use in areas where sea-salt concentrations are quite high, such as at potential intermediate depth drilling sites at relatively low altitude in Antarctica.

\section{Conclusion}

The features, at all scales, of the temperature-corrected electrical records seem to be explained, and almost completely controlled, by the chemical content of the ice. In general, the most striking feature not so far explicitly mentioned is the uniformity of the relationships between electrical properties and chemistry through the data set. The relationship between ECM and DEP signals, between electrical signals and oxygen isotope ratio, and between electrical signals and $\mathrm{Ca}$, are rather tightly defined, and do not seem to vary systematically with depth. This suggests that any changes in fabric, crystal size, location of impurities, or other factors that might vary with age or depth, do not significantly alter the conduction process or the effect of chemical impurities on this process.

The main product extracted from the electrical records is a profile of the background acidity of the atmosphere. This varies dramatically from warm periods, when ice is acidic, to cold periods where it is alkaline. The acidity is strongly determined by the amount of neutralizing alkaline dust present, and this introduces a highly nonlinear feedback between climate and acidity, which is one of the factors controlling the radiative properties of aerosol and of cloud.

If neutralization occurred en route to Greenland, then the usual sulphuric acid or ammonium sulphate aerosols that serve as cloud condensation nuclei ( $\mathrm{CCN}$ ) would likely have been replaced by calcium sulphate (and possibly calcium nitrate). Since calcium sulphate is rather insoluble, it is unlikely to give efficient CCN. A lower CCN density is expected to cause a decrease in cloud albedo and to act as a feedback increasing temperatures [Charlson et al., 1987]. However, at present we cannot say over how large an area of the northern hemisphere acidic aerosol would be lost, or even if neutralization really occurs in the aerosol, and not just in the ice after deposition. The radiative effects are also complicated because the huge increase in dust content of the atmosphere would in itself have an effect, and air masses en route to Greenland from both North America and Europe would have been passing over high-albedo ice surfaces during ice ages. Nonetheless, this is a possible feedback that should be considered more closely.

Similarly, the acidity of precipitation is often an important factor in determining the ecology of freshwater bodies, so that this may also be related to climate in a very nonlinear way. More thought about the sources of acidity to Greenland snow is needed to assess the geographical scope of these conclusions, and it is crucial that we develop a better understanding of the relationship between air and snow concentrations for acidic gases [Dibb et al., 1994].

Finally, the experience of GRIP has highlighted a number of areas in which the electrical methods can be improved to give still more precise data. A number of questions about electrical conduction mechanisms (particularly in alkaline ice) remain, and theoretical studies to explain these are required.

Acknowledgments. This work is a contribution to the Greenland Ice Core Project (GRIP), a European Science Foundation program with eight nations (Belgium, Denmark, France, Germany, Iceland, Italy, Switzerland, and United Kingdom), and the EC, collaborating to drill through the central part of the Greenland ice sheet.

\section{References}

Camplin, G.C., J.W. Glen, and J.G. Paren, Theoretical models for interpreting the dielectric behaviour of HF-doped ice, J. Glaciol., 2I, 123-142, 1978.

Chappellaz, J., T. Blunier, D. Raynaud, J. M. Barnola, J. Schwander, and B. Stauffer, Synchronous changes in atmospheric $\mathrm{CH}_{4}$ and Greenland climate between 40 and $8 \mathrm{kyr}$ BP, Nature, 366, 443-445, 1993.

Charlson, R. J., J. E. Lovelock, M. O. Andreae, and S. G. Warren, Oceanic phytoplankton, atmospheric sulphur, cloud albedo and climate, Nature, 326, 655-661, 1987.

Clausen, H. B., C. U. Hammer, J. Christensen, C. S. Hvidberg, D. DahlJensen, M. Legrand, and J. P. Steffensen, 1250 years of global volcanism as revealed by central Greenland ice cores, in Ice Core Studies of Global Biogeochemical Cycles, Springer-Verlag, New York, in press, 1995

Dansgaard, W., et al., Evidence for general instability of past climate from a 250-kyr ice-core record, Nature, 364, 218-220, 1993.

Dibb, J. E., R. W. Talbot, and M. H. Bergin, Soluble acidic species in air and snow at Summit, Greenland, Geophys. Res. Lett., 21, 1627-1630, 1994.

Fuhrer, K., A. Neftel, M. Anklin, and V. Maggi, Continuous measurements of hydrogen peroxide, formaldehyde, calcium and ammonium concentrations along the new GRIP core from Summit, central Greenland, Atmos. Environ., 27A, 1873-1880, 1993.

GRIP Project Members, Climate instability during the last interglacial period recorded in the GRIP ice core, Nature, 364, 203-207, 1993.

Grootes, P. M., M. Stuiver, J. W. C. White, S. Johnsen, and J. Jouzel, Comparison of oxygen isotope records from the GISP2 and GRIP Greenland ice cores, Nature, 366, 552-554, 1993.

Hammer, C. U., Acidity of polar ice cores in relation to absolute dating, past volcanism, and radio echoes, $J$. Glaciol., 25, 359-372, 1980.

Hammer, C. U., Initial direct current in the buildup of space charges and the acidity of ice cores, J. Phys. Chem., 87, 4099-4103, 1983.

Hammer, C. U., Dating by physical and chemical seasonal variations and reference horizons, in Dahlem Workshop Reports. Physical, Chemical and Earth Science Research Reports, vol. 8, The Environmental Record in Glaciers and Ice Sheets, edited by $\mathrm{H}$. Oeschger and C. C. Langway Jr., pp. 99-121, Wiley-Interscience, New York, 1989.

Hammer, C. U., H. B. Clausen, and W. Dansgaard, Greenland ice sheet evidence of post-glacial volcanism and its climatic impact, Nature, 288, 230-235, 1980.

Harnmer, C. U., H. B. Clausen, W. Dansgaard, A. Neftel, P. Kristinsdottir, and E. Johnson, Continuous impurity analysis along the Dye 3 deep core, in Greenland Ice Core: Geophysics, Geochemistry and the Environment, Geophys. Mongr. Ser., vol. 33, edited by C. C. Langway Jr., H. Oeschger, and W. Dansgaard, pp. 90-94, AGU, Washington, D.C., 1985.

Herron, M. M., Impurity sources of $\mathrm{F}, \mathrm{Cl}^{-}, \mathrm{NO}_{3}{ }_{3}$ and $\mathrm{SO}_{4}{ }^{2-}$ in Greenland and Antarctic precipitation, J. Geophys. Res., 87, 3052-3060, 1982.

Hobbs, P. V., Ice Physics, Clarendon, Oxford, 1974.

Johnsen, S. J., H. B. Clausen, W. Dansgaard, K. Fuhrer, N. Gundestrup, C. U. Hammer, P. Iversen, J. Jouzel, B. Stauffer, and J. P. Steffensen, Irregular glacial interstadials recorded in a new Greenland ice core, Nature, 359, 311-313, 1992a.

Johnsen, S. J., H. B. Clausen, W. Dansgaard, N. S. Gundestrup, M. Hansson, P. Jonsson, J. P. Steffensen, and A. E. Sveinbjфmsdottir, A "deep" ice core from East Greenland, Medd. Gronl. Geosci. 29, 3-22, $1992 b$.

Legrand, M., M. de Angelis, T. Staffelbach, A. Neftel, and B. Stauffer, Large perturbations of ammonium and organic acids content in the Summit-Greenland ice core. Fingerprint from forest fires?, Geophys. Res. Lett., 19, 473-475, 1992.

Mayewski, P. A., L. D. Meeker, S. Whitlow, M. S. Twickler, M. C. Morrison, R. B. Alley, P. Bloomfield, and K. Taylor, The atmosphere during the Younger Dryas, Science, 261, 195-197, 1993.

Moore, J. C., High resolution dielectric profiling of ice cores, J. Glaciol., 39, 245-248, 1993.

Moore, J. C., and J. G. Paren, A new technique for dielectric logging of Antarctic ice cores, J. Phys., 48, C1/155-C1/160, 1987. 
Moore, J. C., R. Mulvaney, and J. G. Paren, Dielectric stratigraphy of ice: A new technique for determining total ionic concentrations in polar ice cores, Geophys. Res. Lett., 16, 1177-1180, 1989.

Moore, J. C., J. G. Paren, and H. Oerter, Sea salt dependent electrical conduction in polar ice, J. Geophys. Res., 97, 19803-19812, 1992a.

Moore, J. C., E. W. Wolff, H. B. Clausen, and C. U. Hammer, The chemical basis for the electrical stratigraphy of ice, J. Geophys. Res., 97, 1887-1896, 1992b.

Moore, J. C., E. W. Wolff, H. B. Clausen, C. U. Hammer, M. R Legrand, and K. Fuhrer, Electrical response of the Summit-Greenland ice core to ammonium, sulphuric acid, and hydrochloric acid, Geophys. Res. Lett., 21, 565-568, 1994.

Steffensen, J. P., Analysis of the seasonal variation in dust, $\mathrm{Cl}^{2}, \mathrm{NO}_{3}^{-}$, and $\mathrm{SO}_{4}{ }^{2}$ in two central Greenland firn cores, Ann. Glaciol., 10, 171-177, 1988.

Taylor, K. C., C. U. Hammer, R. B. Alley, H. B. Clausen, D. DahlJensen, A. J. Gow, N. S. Gundestrup, J. Kipfstuhl, J. C. Moore, and E. D. Waddington, Electrical conductivity measurements from the GISP2 and GRIP Greenland ice cores, Nature, 366, 549-552, 1993a.

Taylor, K. C., G. W. Lamorey, G. A. Doyle, R. B. Alley, P. M. Grootes, P. A. Mayewski, J. W. C. White, and L. K. Barlow, The "flickering switch" of late Pleistocene climate change, Nature, 361, 432-436, 1993b.
Whitlow, S., P. A. Mayewski, and J. E. Dibb, A comparison of major chemical species seasonal concentration and accumulation at the South Pole and Summit, Greenland, Atmos. Environ., 26A, 2045-2054, 1992

Wolff, E. W., Nitrate in polar ice, in Ice Core Studies of Global Biogeochemical Cycles, Springer-Verlag, New York, in press, 1995.

H.B. Clausen and C.U. Hammer, Niels Bohr Institute, Department of Geophysics, Haraldsgade 6, DK 2200 Copenhagen N, Denmark. (email: hbc@gfy.ku.dk; cuh@gfy.ku.dk)

K. Fuhrer, Physikalisches Institut, Universität Bern, Sidlerstrasse 5, CH-3012 Bern, Switzerland. (e-mail: kfuhrer@phil.unibe.ch)

J. Kipfstuhl, Alfred Wegener Institut, Columbusstrasse, D-27515

Bremerhaven, Germany. (e-mail: kipfstuhl@awi-bremerhaven.de)

J.C. Moore, Arctic Centre, University of Lapland, Box 122, SF96101 Rovaniemi, Finland. (e-mail: jmoore@roisrv.urova.fi)

E.W. Wolff, British Antarctic Survey, High Cross, Madingley

Road, Cambridge, CB3 0ET, England. (e-mail: e.wolff@bas.ac.uk)

(Received November 23, 1994; revised March 23, 1995; accepted March 23, 1995.) 